\title{
Heparanase powers a chronic inflammatory circuit that promotes colitis-associated tumorigenesis in mice
}

Immanuel Lerner, ${ }^{1}$ Esther Hermano, ${ }^{1}$ Eyal Zcharia, ${ }^{2}$ Dina Rodkin, ${ }^{1}$ Raanan Bulvik, ${ }^{1}$ Victoria Doviner, ${ }^{3}$ Ariel M. Rubinstein, ${ }^{1}$ Rivka Ishai-Michaeli, ${ }^{1}$ Ruth Atzmon, ${ }^{1}$ Yoav Sherman, ${ }^{3}$ Amichay Meirovitz, ${ }^{1}$ Tamar Peretz, ${ }^{1}$ Israel Vlodavsky, ${ }^{2}$ and Michael Elkin ${ }^{1}$

\begin{abstract}
'Sharett Institute, Hadassah-Hebrew University Medical Center, Jerusalem, Israel. ${ }^{2}$ Cancer and Vascular Biology Research Center, The Rappaport Faculty of Medicine, Technion, Haifa, Israel. ${ }^{3}$ Department of Pathology, Hadassah-Hebrew University Medical Center, Jerusalem, Israel.
\end{abstract}

\begin{abstract}
Ulcerative colitis (UC) is a chronic inflammatory bowel disease that is closely associated with colon cancer. Expression of the enzyme heparanase is clearly linked to colon carcinoma progression, but its role in UC is unknown. Here we demonstrate for what we believe to be the first time the importance of heparanase in sustaining the immune-epithelial crosstalk underlying colitis-associated tumorigenesis. Using histological specimens from UC patients and a mouse model of dextran sodium sulfate-induced colitis, we found that heparanase was constantly overexpressed and activated throughout the disease. We demonstrate, using heparanase-overexpressing transgenic mice, that heparanase overexpression markedly increased the incidence and severity of colitis-associated colonic tumors. We found that highly coordinated interactions between the epithelial compartment (contributing heparanase) and mucosal macrophages preserved chronic inflammatory conditions and created a tumor-promoting microenvironment characterized by enhanced NF- $\kappa$ B signaling and induction of STAT3. Our results indicate that heparanase generates a vicious cycle that powers colitis and the associated tumorigenesis: heparanase, acting synergistically with the intestinal flora, stimulates macrophage activation, while macrophages induce production (via TNF- $\alpha$-dependent mechanisms) and activation (via secretion of cathepsin L) of heparanase contributed by the colon epithelium. Thus, disruption of the heparanase-driven chronic inflammatory circuit is highly relevant to the design of therapeutic interventions in colitis and the associated cancer.
\end{abstract}

\section{Introduction}

Heparanase is a predominant mammalian enzyme that cleaves heparan sulfate (HS), the principle polysaccharide associated with the cell surface and ECM of a wide range of tissues (1). HS plays a key role in ECM integrity, barrier function, and cell-ECM interactions. In addition, HS moieties in the ECM sequester heparin-binding growth factors (i.e., bFGF, VEGF, and HGF), thereby controlling their accessibility, function, and mode of action $(1,2)$. Heparanase cleavage of HS in the ECM, particularly in epithelial and subendothelial basement membranes, leads to disassembly of extracellular barriers, release of HS-bound angiogenic factors and/ or growth factors, and generation of bioactive HS fragments that promote growth factor-receptor binding, dimerization, and signaling (3-5). Thus, heparanase is involved in fundamental biological phenomena associated with cancer progression, including cell survival, invasion, proliferation, neovascularization, and creation of a growth-permissive microenvironment (3, 6-9).

The role of heparanase in tumorigenesis implies that under normal physiological conditions the enzyme should be kept tightly regulated. Regulation of gene transcription represents one type of control mechanism. Indeed, the heparanase gene is overexpressed in essentially all human tumors examined (reviewed in ref. 3). Posttranslational processing represents an additional key regulatory mechanism. Heparanase is produced as a latent $65-\mathrm{kDa}$ proenzyme whose activation involves proteolytic cleavage, brought about pre-

Conflict of interest: The authors have declared that no conflict of interest exists. Citation for this article: J Clin Invest. 2011;121(5):1709-1721. doi:10.1172/JCI43792. dominantly by cathepsin $\mathrm{L}$ (CatL), yielding an enzymatically active heterodimer composed of 8- and 50-kDa subunits (10).

Heparanase contribution to colon carcinoma progression is well documented. While normal colonic epithelium does not express heparanase, expression of the enzyme is a characteristic feature of colon carcinoma, correlating with poor prognosis (11-14). Transfection of the heparanase gene into colon carcinoma cell lines results in augmented aggressiveness and enhanced tumor growth $(11,14)$.

The role of heparanase in inflammation has attracted less attention. Prior to cloning of the heparanase gene, heparanase activity originating in activated cells of the immune system has been found to contribute to their ability to penetrate blood vessel walls and accumulate in target organs (15). However, it is becoming increasingly clear that immunocytes are not the primary source of the enzyme in inflammation. Investigating chronic inflammatory conditions of the gastrointestinal tract, we previously found that heparanase is preferentially expressed by colonic epithelium in Crohn disease and ulcerative colitis (UC) (16), collectively known as inflammatory bowel disease (IBD).

The most feared long-term complication of IBD (in particular, UC) is colon carcinoma, as patients with UC have a risk of colorectal cancer that is an order of magnitude higher than in the normal population (17). In fact, colon carcinoma represents a paradigm for the association between inflammation and cancer (18). Based on the preferential expression of heparanase in chronically inflamed colonic epithelium involvement of the enzyme in colon tumorigenesis, and increased incidence of colon cancer in UC patients, we hypothesized that stimulation of heparanase expression may play an important 
role in the pathogenesis of UC, representing a mechanistic link between inflammation and cancer. Our research was undertaken to elucidate the biological significance of heparanase in chronic colitis and related tumorigenesis. Utilizing UC tissue specimens, along with a mouse model of colitis-associated cancer induced by the carcinogen azoxymethane (AOM), followed by the inflammatory agent dextran sodium sulfate (DSS) (19), we found that heparanase is constantly overexpressed by the colonic epithelium in experimental colitis and UC during both the acute and chronic phases of the disease. Moreover, heparanase overexpression preserves chronic inflammatory conditions in DSS colitis and thus creates a tumor-promoting microenvironment characterized by enhanced NF-אB signaling (18, $20)$, augmented levels of cyclooxygenase-2 (COX-2) $(17,21)$, STAT3 induction (22), and increased vascularization. Furthermore, we identified what we believe is a novel biological mechanism contributing to chronic colitis and the associated colon tumorigenesis. This mechanism involves a self-sustained cycle through which heparanase of epithelial origin, acting synergistically with the local flora and cytokine milieu, facilitates abnormal activation of innate immune cells (i.e., macrophages), which in turn stimulate further production of the enzyme by the colonic epithelium. Moreover, in chronic colitis, activated macrophages represent a primary source of CatL responsible for proteolytic activation of latent heparanase. Thus, disruption of the heparanase-driven chronic inflammatory circuit might be highly relevant to the design of therapeutic interventions in UC and the associated cancer.

\section{Results}

\section{Overexpression of heparanase in clinical and experimental chronic colitis}

Applying immunohistochemical staining to examine heparanase expression in colon specimens from UC patients $(n=10)$, as well as in control samples derived from healthy colonic tissue specimens $(n=29)$ (Figure 1), we extended our previous report (16) on preferential expression of heparanase in UC. Notably, while heparanase expression was barely detected in healthy colon epithelium (negative staining in 24 biopsies and faint staining in 5 biopsies) (Figure 1A), in UC specimens the epithelial lining showed a marked expression of heparanase in both the acute and chronic phases of the disease (strong staining in all biopsies; Figure 1A). Given the suggested role of heparanase in colon tumorigenesis $(12-14,23)$, it is important to note that a strong heparanase staining was detected during the chronic phase in the immature glands that had recently formed in the healing mucosa and that displayed initial dysplastic-like changes typical for this phase of UC (Figure 1A). In all phases, inflammatory cells in the involved areas showed little or no heparanase expression. We next studied the tempo-spatial pattern of heparanase expression in DSS-induced colitis. Repeated oral administration of DSSsupplemented water to mice is a reliable model of UC, recapitulating characteristic changes observed in the colon of UC patients. DSS causes an acute inflammatory reaction and ulceration in the colon (24), and when 3 cycles (7 days each, with 14-day intervals) of DSS administration are applied, acute inflammation is followed by chronic colitis (24). Moreover, 3 cycles of DSS subsequent to a single AOM pretreatment result in development of colon tumors in nearly $100 \%$ of the treated mice (19), representing a well-established model of colitis-associated cancer. In addition, DSS alone may cause colonic tumors in almost $50 \%$ of the treated mice when the DSS cycles are repeatedly administered 9 times (25), further dem- onstrating the relevance of this model to inflammation-induced tumorigenesis. In our initial experiments $\mathrm{BALB} / \mathrm{c}$ mice were given 3 cycles of DSS-supplemented water, as indicated in Figure 1B. Mice were sacrificed on experimental day 110 and their colon excised, and heparanase expression was assessed by real-time PCR, Western blotting, and immunostaining. A marked increase in heparanase mRNA (Figure 1C), protein (Figure 1D, and Figure 1, E and G), and enzymatic activity (Figure $1 \mathrm{~F}$ ) was readily detected in the colon during all phases of DSS-induced colitis. Moreover, Western blot analysis revealed an even higher increase in the amount of proteolytically activated $50-\mathrm{kDa}$ heparanase at all phases of DSS colitis (Figure 1, D and E). The 50-kDa enzyme represents an N-terminally processed heparanase, which is at least 100 -fold more active than the $65-\mathrm{kDa}$ proenzyme (7). CatL is the predominant protease responsible for processing and activation of proheparanase (10). In accordance, increased levels of CatL mRNA (Figure 1C) and protein (Figure 1, D and G) were detected in the mouse colonic tissue at corresponding time points (discussed below).

\section{Heparanase overexpression increases the incidence and severity of colitis-associated tumors}

We next applied the AOM/DSS model to investigate the possible contribution of heparanase to colitis-associated carcinoma. Unlike UC patients, in which increased heparanase expression is constantly preserved (Figure 1A), in DSS colitis, heparanase levels gradually decreased during the chronic phase (Figure 1, C-E). Thus, to assess the precise role of heparanase in colitis-related tumorigenesis, we utilized heparanase transgenic ( $\mathrm{Hpa} \mathrm{Tg}$ ) mice along with their WT counterparts. Hpa Tg mice (26) have been extensively used in studies on the role of heparanase in angiogenesis (27), bone turnover (28), diabetic nephropathy (29), arterial stenosis (30), and amyloid diseases (31). Hpa Tg mice express elevated levels of heparanase in colonic epithelium (Supplemental Figure 1, A-D; supplemental material available online with this article; doi:10.1172/JCI43792DS1), but not in splenocytes (26), which closely resembles the heparanase expression pattern in UC patients. Of note, analysis of colonic tissue sections immunostained with antibodies directed against proliferating cell nuclear antigen (PCNA) and activated (cleaved) caspase-3 (Supplemental Figure 1E) revealed no differences in proliferation/apoptosis rate in colonic epithelium of healthy Hpa Tg versus WT mice.

A single dose of AOM was injected to 10 -week-old Hpa Tg and WT mice prior to 3 cycles of DSS treatment (as indicated in Figure $1 \mathrm{~B}$ and described in Methods). Mice were sacrificed on day 110 of the experiment and their colon removed and examined for tumor formation. Easily detectable colonic tumors, graded by histological examination as adenocarcinomas (well- to moderately differentiated), were present in all colons (Figure 2, A and B). However, a macroscopically apparent and statistically significant increase in tumor incidence $(P=0.026)$ was readily detected in Hpa Tg mice as compared with their WT littermates (Figure 2, A-C). In addition, heparanase overexpression markedly enhanced the severity of colitis-associated colonic tumors, as evidenced by increased tumor size ( $P=0.020$; Figure 2C), vascular density (Figure 2, E and F), and considerable augmentation in the shift of $\beta$-catenin from the cell membrane to a cytoplasmic/nuclear localization, observed in $\mathrm{Hpa}$ Tg mice compared with WT mice (Figure 2D). Moreover, when 3 DSS cycles were administered alone, without AOM pretreatment, none of the WT mice developed colonic tumors during the observation period (although pre-cancerous changes were noted in $25 \%$ of WT mice), whereas colonic tumors (mostly moderately differenti- 

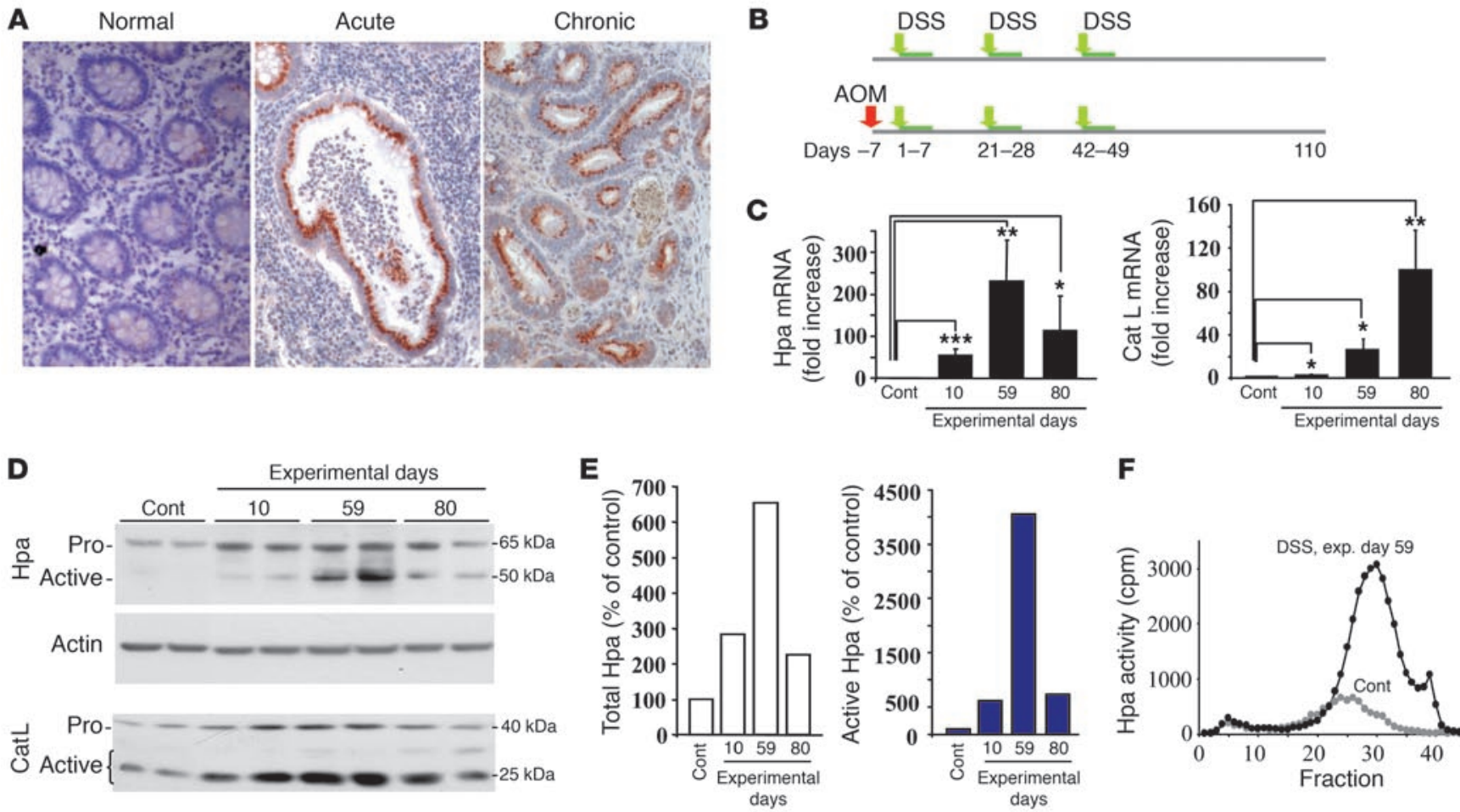

$\mathbf{F}$

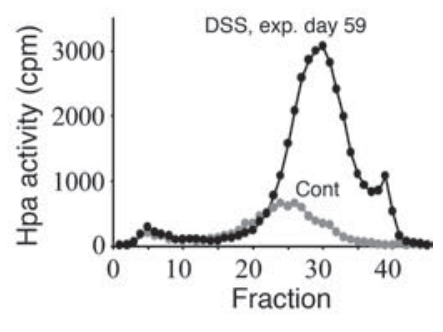

G

Experimental day
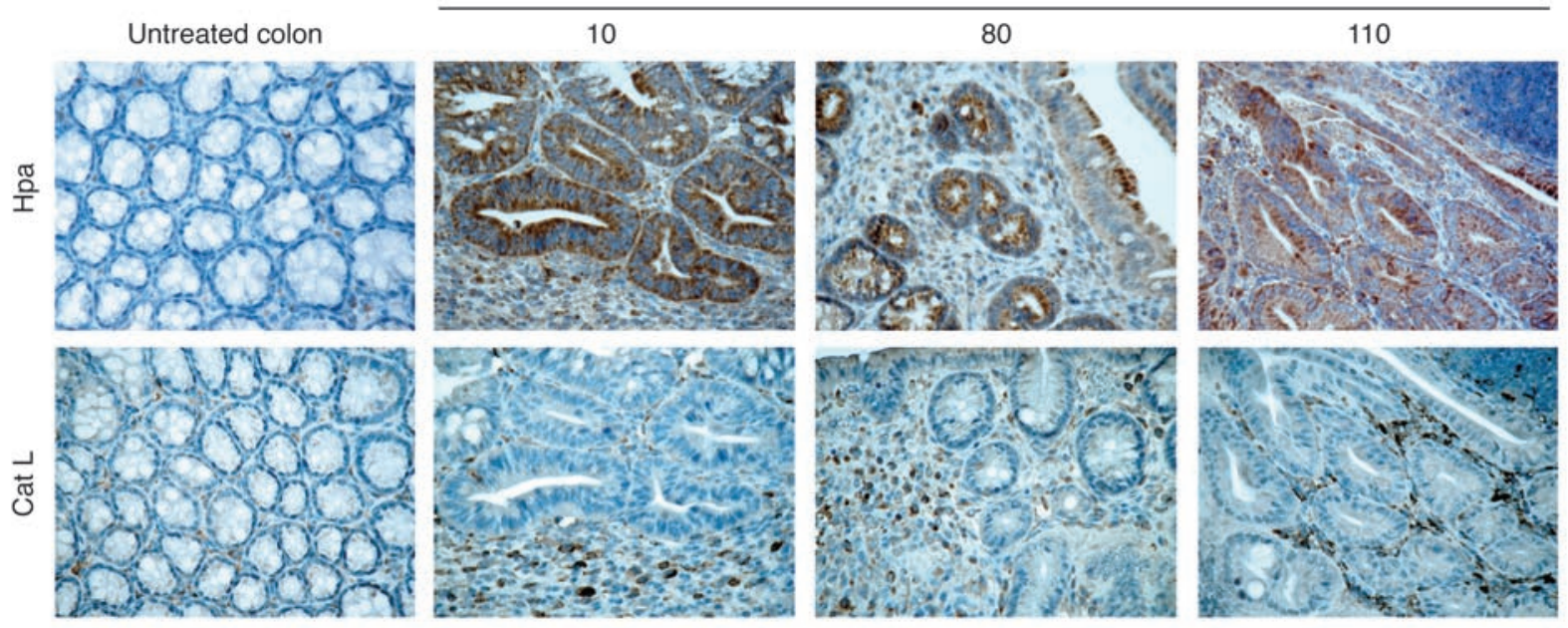

Figure 1

Expression of heparanase and CatL is induced during the course of colitis. (A) Heparanase expression in acute and chronic phases of UC. Tissue specimens derived from normal colon tissue (left) and UC patients in acute (middle) and chronic (right) phases of the disease were stained with anti-heparanase antibody (red staining). Photographs are representative of control $(n=29)$ and UC $(n=10)$ samples (original magnification, $\times 200$ ). (B) Schematic representation of mouse model of DSS colitis (top) and AOM/DSS-induced colitis-associated carcinoma (bottom), induced as described in Methods. Mouse colonic tissues were harvested at indicated time points and analyzed as described below for $\mathbf{C}-\mathbf{G}$. (C) Heparanase (Hpa; left) and CatL (right) mRNA expression during the course of DSS-induced colitis, measured by qRT-PCR and normalized to actin mRNA $(n=5){ }^{*} P<0.05,{ }^{* *} P<0.01,{ }^{* * *} P<0.001$. (D) Heparanase and CatL protein levels. Lysates of distal colons were harvested at the indicated time points and analyzed for heparanase and CatL protein by immunoblotting. Pro-, latent $65 \mathrm{kDa}$ proenzyme; Active-, enymaticallyactive $50 \mathrm{kDa}$ heparanase. (E) Densitometric quantification of total (65 kDa and $50 \mathrm{kDa}$, left) and active (50 kDa, right) heparanase presented in D. (F) Heparanase activity. Punch biopsies were harvested on day 59 from DSS-untreated (Cont) and treated (DSS) mice and cultured for 24 hours. Heparanase activity was determined in the conditioned medium. (G) Immunostaining (brown) of mouse colonic serial tissue sections with anti-heparanase (top) and CatL (bottom) antibodies. Note heparanase staining in the epithelial compartment and CatL staining in the stromal compartment (original magnification, $\times 200$ ). 

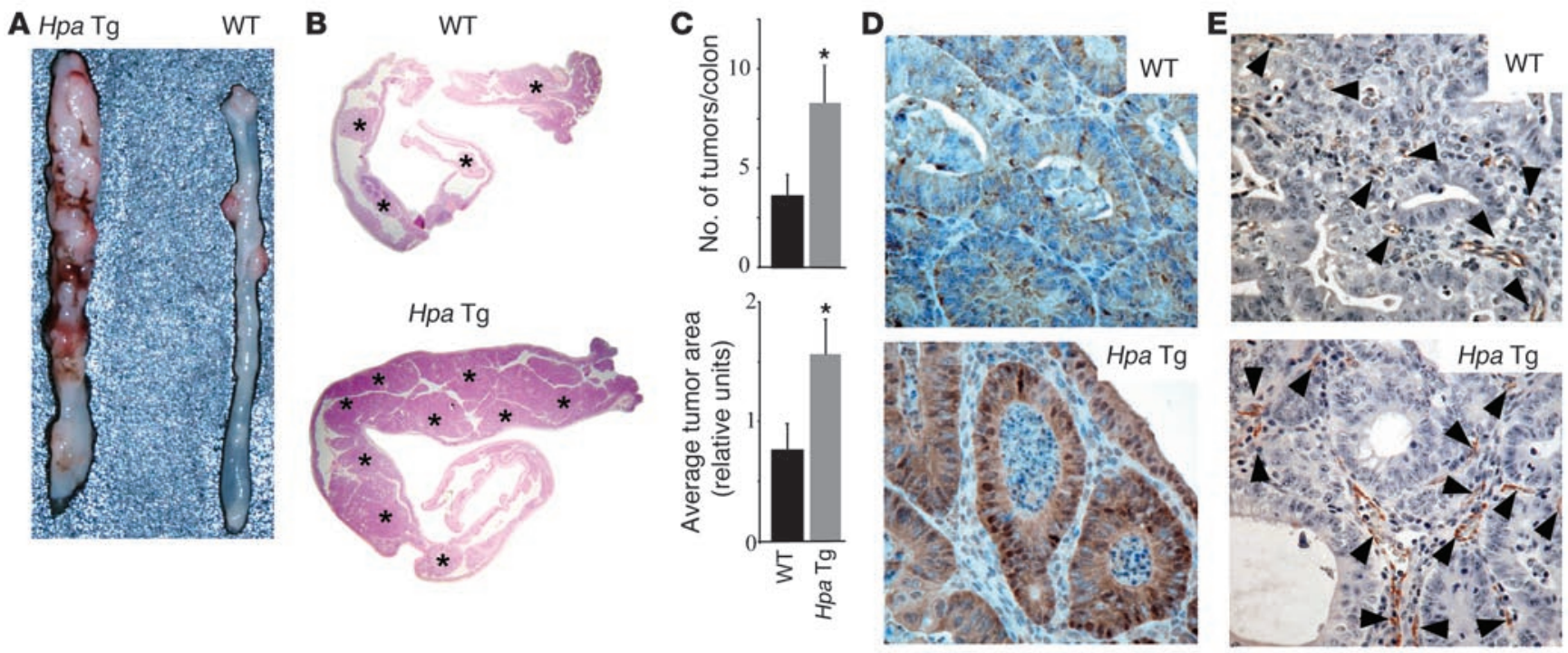

$\mathbf{F}$

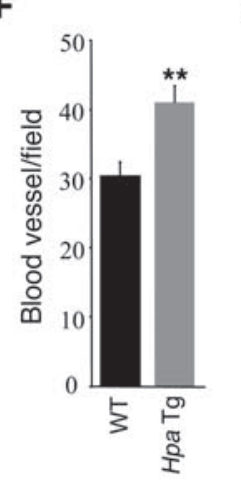

G

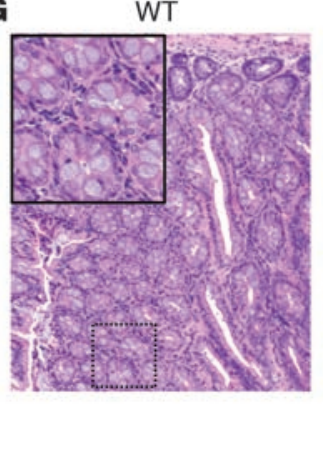

Hрa Tg

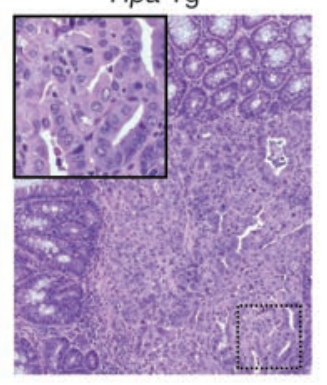

H
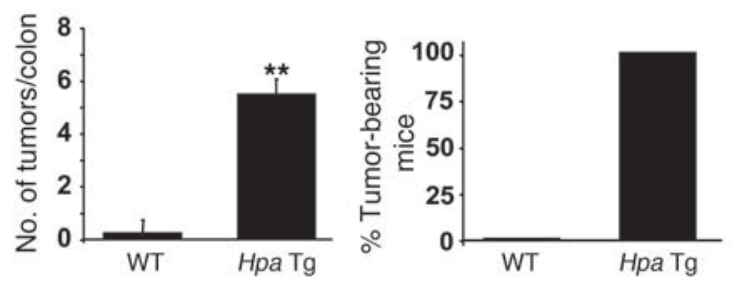

Figure 2

Overexpression of heparanase confers increased susceptibility to colitis-associated tumors in AOM/DSS-treated and DSS-treated mice. (A-F) AOM/DSS-treated mice. (G and H) DSS-treated mice. (A) Gross appearance. Colons $(n=9)$ were removed on day 110 from AOM/DSS-treated mice, opened longitudinally, washed in PBS, and photographed. (B) Sub-gross examination (original magnification, $\times 3$ ) and (C) quantification of colonic tumors detected on day 110 (AOM/DSS-treated mice) revealed increased tumor incidence (C, top) and burden (C, bottom) in $\mathrm{Hpa}$ Tg colon (gray bars) versus WT colon (black bars) $(n=9)$. (D) Immunostaining with anti- $\beta$-catenin antibody reveals enhanced expression and nuclear localization of $\beta$-catenin in $\mathrm{Hpa} \mathrm{Tg} \mathrm{(bottom)} \mathrm{versus} \mathrm{WT} \mathrm{(top)} \mathrm{colonic} \mathrm{tumors} \mathrm{(original} \mathrm{magnification,} \times 400$ ). (E and $\mathbf{F}$ ) Increased vascular density in $\mathrm{Hpa} \mathrm{Tg}$ versus WT colonic tumors evaluated by immunostaining with anti-CD31 antibody (original magnification, $\times 400)(E)$ and quantified by blind counting of blood vessels per microscopic field $(\mathbf{F})$. (G and $\mathbf{H})$ DSS-induced chronic colitis (without AOM administration) results in colonic tumor formation in Hpa Tg but not in WT mice. (G) Representative microphotographs of histological sections showing the presence of tumors in colons derived from Hpa Tg (bottom) but not WT (top) mice. Magnification, $\times 100$; inset: boxed regions shown at higher magnification $(\times 400)$. (H) Number of tumors per colon (top) and percentage of tumor-bearing animals (bottom) in Hpa Tg versus WT mice. Error bars represent mean $\pm \mathrm{SD}$. ${ }^{*} P<0.05,{ }^{* \star} P<0.01$.

ated adenocarcinomas) were easily seen by histological examination in $90 \%$ of the Hpa Tg mice (Figure 2, G and H). Notably, mice treated with AOM alone (without DSS) did not develop tumors during the observation period regardless of genotype, emphasizing the essential role of inflammation in this experimental system.

\section{Heparanase overexpression preserves chronic inflammatory conditions in DSS colitis}

We investigated whether the increased tumor incidence and severity in Hpa Tg mice is due to an exacerbated colonic inflammatory phenotype. Interestingly, during the acute phase of DSS colitis (days 1-10 of the experiment; ref. 24), we were unable to detect a more severe inflammatory phenotype in Hpa Tg compared with WT mice (Supplemental Figure 2). The rate of weight loss (a characteristic feature of acute DSS colitis; ref. 24) was not statistically significant different between Hpa Tg and WT mice (Supplemental Figure 2A). Moreover, in both Hpa Tg and WT mice a similar degree of leukocyte infiltration and epithelial cell damage (including multifocal dropouts of entire crypts and ulceration) were seen in all parts of the colon (Supplemental Figure 2B). Immunostaining revealed no differences in the extent of infiltration of neutrophils, the first recruited effectors of the acute inflammatory response $(32,33)$, between $\mathrm{Hpa}$ Tg and WT mice on day 10 of the experiment (Supplemental Figure $2 \mathrm{~B}$ ). In both genotypes the same degree of increase in mRNA encoding for pro-inflammatory proteins (i.e., TNF- $\alpha$, iNOS, COX-2) was observed during the acute phase of DSS inflammation (Supplemental Figure 2C). ELISA determination of TNF- $\alpha$ secreted ex vivo by cultured colon punch biopsies revealed $13.8 \pm 7.3 \mathrm{pg} / \mathrm{ml}$ in Hpa Tg 
compared with $33.4 \pm 3.5 \mathrm{pg} / \mathrm{ml}$ in WT mice, further demonstrating the lack of exacerbated acute inflammation in Hpa Tg mice.

In contrast to the acute phase, heparanase overexpression profoundly affected the chronic phase of DSS-induced colitis, as demonstrated by the different inflammatory phenotypes expressed by Hpa Tg and WT mice on experimental day 80 (1 month after cessation of the last DSS cycle). Microscopic examination of H\&Estained colonic sections revealed persistent mucosal infiltration by immunocytes in Hpa Tg mice compared with little or no infiltration in WT mice (Figure 3B). This infiltration was accompanied by high occurrence of dysplastic glands (Figure 3B). Since angiogenesis is recognized as an integral component of chronic inflammation in both human UC (34) and experimental mouse colitis (35), we assessed the vascular density, applying immunostaining with antibodies directed against CD31 (Figure 3C), and found that colons of Hpa Tg mice contained significantly more blood vessels compared with WT mice (Figure 3J). There was no difference in vascular density between colonic tissues derived from healthy untreated WT and Hpa Tg mice (data not shown).

In addition to histopathological evaluation, we examined differences in chronic inflammatory phenotype between Hpa $\mathrm{Tg}$ and WT mice at the molecular level. Since TNF- $\alpha$ is an important player in the inflammatory cascade in both human UC and DSS experimental colitis, we first analyzed TNF- $\alpha$ production, applying ex vivo-cultured punch biopsies harvested from the colon of DSS-treated mice on day 80 of the experiment. At this stage, the amounts of TNF- $\alpha$ secreted by WT colonic explants were below the level detectable by ELISA (similar to explants harvested from healthy untreated colon), while $30.0 \pm 6.1 \mathrm{pg} / \mathrm{ml}$ TNF- $\alpha$ were measured in medium conditioned ex vivo by colonic explants harvested from Hpa Tg mice (Figure $3 \mathrm{H}$ ). In agreement, increased levels of mRNA encoding for TNF- $\alpha$ were determined by real-time PCR in Hpa Tg versus WT colons (Figure 3I).

TNF- $\alpha$ is a major inducer of NF- $\kappa \mathrm{B}$ activation, and enhanced NF- $\mathrm{KB}$ signaling is the hallmark of chronic intestinal inflammation $(18,20)$. We therefore compared activation of the NF- $\kappa B$ pathway between WT and Hpa Tg mice. NF- $\mathrm{KB}$ is normally sequestered in the cytoplasm by means of association with an inhibitory protein,

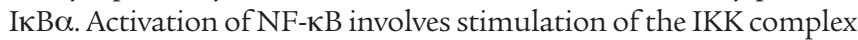
which phosphorylates $\mathrm{I} \kappa \mathrm{B} \alpha$, triggering its degradation and nuclear

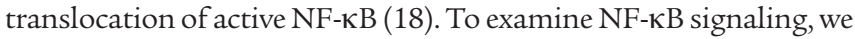

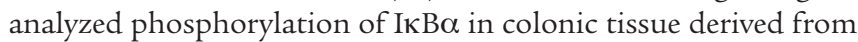
WT and Hpa Tg mice on day 80 of the experiment, immunostaining with an anti-phospho-IкB $\alpha(\mathrm{pI \kappa} B \alpha)$ antibody. As shown in Figure $3 \mathrm{D}$, a high number of $\mathrm{pI \kappa B} \alpha$-positive cells was observed in $\mathrm{Hpa} \mathrm{Tg}$ compared with WT colon. Cells positive for $\mathrm{PI \kappa B} \alpha$ were found in the stroma, and to a lesser extent in the epithelial compartment of $\mathrm{Hpa}$ $\mathrm{Tg}$ colon. Activation of NF- $\mathrm{KB}$ signaling was further confirmed by increased number of cells positive for nuclear phospho-p $65 \mathrm{NF}-\kappa \mathrm{B}$, detected by immunofluorescent analysis of $\mathrm{Hpa}$ Tg versus WT colon (Supplemental Figure 3). Consistent with these findings, markedly increased levels of several NF-КB-inducible cytokines (36) (i.e., IL-1, IL-6, macrophage inflammatory protein-1 [MIP-1], and MIP-2) tightly associated with chronic colitis and/or the associated tumorigenesis (22,37-41), were detected in Hpa Tg versus WT colon, applying mouse cytokine antibody array (data not shown) and confirmed by quantitative real-time PCR (qRT-PCR) (Supplemental Figure $4 \mathrm{~B}$ and data not shown). In addition, increased expression of the NF-кB-regulated genes Bcl2l1 (Supplemental Figure 4B) and Cox2 (Figure 3E) was detected in Hpa Tg colonic tissue.
Notably, some NF-кB-controlled cytokines that were upregulated in Hpa Tg colon, including IL-1, IL-6, and TNF- $\alpha$, play a pivotal role in activation of STAT3, a critical modulator of tumor-promoting chronic inflammation (42-45). We therefore assessed the activation status of STAT3 in our system, by immunostaining with anti-phospho-STAT3 (pSTAT3) antibody. As shown in Figure 3F, a high number of cells positive for nuclear localized PSTAT3 was observed in Hpa Tg as compared with WT colon (primarily in the epithelial compartment). In agreement with the recently established role of STAT3 in enhanced intestinal epithelial cell proliferation during colitis-associated tumorigenesis $(42,43)$, immunostaining with anti-PCNA antibody revealed an increased rate of proliferation of epithelial cells in Hpa Tg colon (Supplemental Figure 4A). Moreover, applying double-immunofluorescent staining with antibodies directed against PCNA and PSTAT3, we demonstrated that STAT activation colocalizes with highly proliferating epithelial cells in $\mathrm{Hpa}$ $\mathrm{Tg}$ colon (Supplemental Figure 4C). A significant increase in the rate of colonic epithelial cell proliferation in Hpa Tg versus WT mice was further confirmed by immunostaining with anti-cyclin D1 (Figure $3, \mathrm{G}$ and $\mathrm{K}$ ), providing a mechanistic explanation for the enhanced tumorigenesis observed in Hpa Tg mice (Figure 2, G and H). Of note, analysis of the apoptotic rate by immunostaining with antibody directed against cleaved caspase- 3 revealed no statistically significant difference between Hpa Tg and WT mice in the percentage of cleaved caspase-3-positive cells (data not shown).

Taken together, these results suggest that the constantly elevated levels of heparanase in Hpa Tg mice (which resemble the observations in UC patients illustrated in Figure 1A) markedly affect the chronic phase of DSS-induced colitis and create a tumor-promoting inflammatory microenvironment via increased vascularization as well as enhanced NF- $\kappa$ B signaling, augmented levels of STAT3inducing cytokines (i.e., IL-6, IL-1, TNF- $\alpha$ ), and STAT 3 activation.

\section{Macrophages represent both cellular targets for heparanase action and regulators of heparanase expression and activity in chronic colitis}

Involvement of heparanase in macrophage activation. The chronic inflammatory microenvironment is characterized by infiltration with mononuclear cells, and macrophages are the dominant cellular players in chronic inflammation $(32,33)$. Lamina propria macrophages represent a major cellular source of TNF- $\alpha$ in IBD and play a key role in the pathogenesis of both human UC (46) and murine chronic colitis (47, 48). Additionally, macrophages are important contributors to tumor initiation and progression $(33,49)$. This effect is mediated, among other mechanisms, by the production of angiogenic and growth-promoting factors (i.e., VEGF, bFGF, HGF, EGF), cytokines (i.e., TNF- $\alpha$ ) and enzymes (i.e., COX-2) $(33,49)$. This led us to examine the involvement of macrophages in our system. Through immunostaining with antibody directed against F4/80 (a mouse macrophage-specific marker; ref. 50), we detected increased macrophage infiltration in the colon of Hpa Tg versus WT mice on day 80 of the chronic DSS colitis model (Figure 4A). Of note, increased macrophage infiltration was also found in colonic tumors observed on day 110 of the AOM/DSS model in Hpa Tg versus WT mice (Supplemental Figure 5A). Macrophages infiltrating the Hpa Tg colon were not only more abundant than in WT colon, but also exhibited an exacerbated pro-inflammatory phenotype, as evidenced by a 3-fold increase (Figure 4C) in percentage of TNF- $\alpha$-positive macrophages visualized by double immunofluorescent staining with anti-TNF- $\alpha$ and anti-F4/80 antibodies (Figure 4B). In support of this notion, double immunofluorescent staining with 


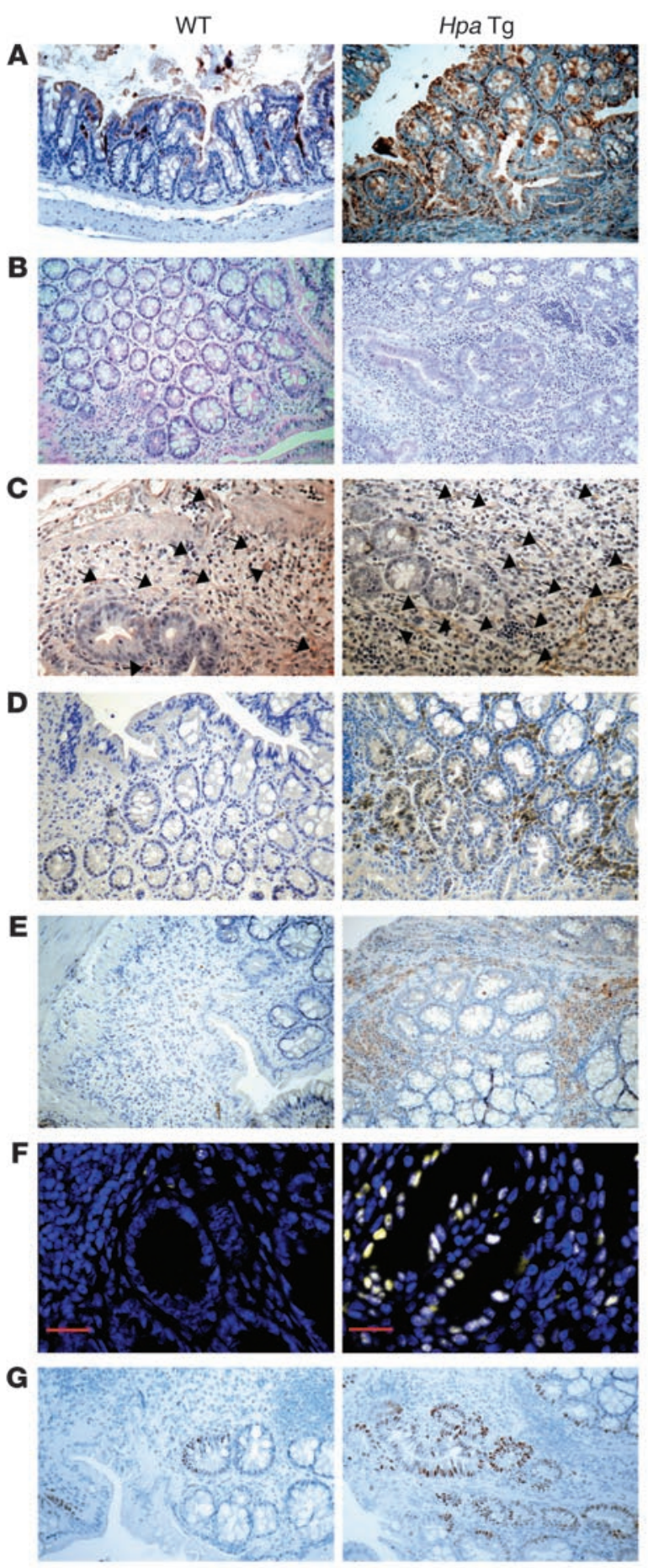

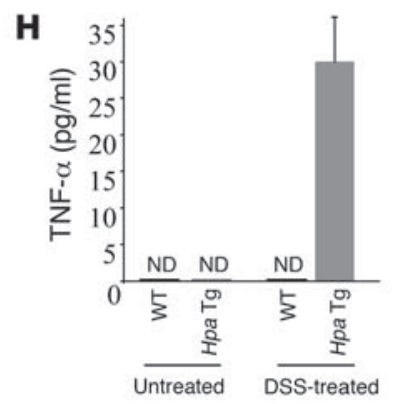
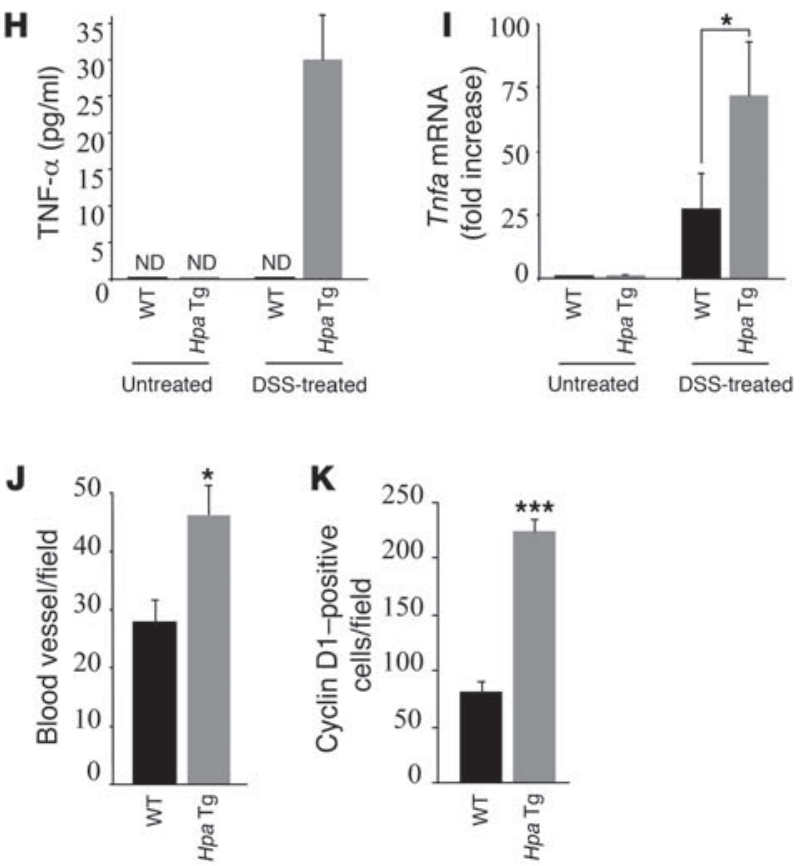

\section{Figure 3}

Heparanase preserves chronic inflammatory conditions in DSS colitis. Colons were obtained from DSS-treated WT (left) and Hpa Tg (right) mice on day 80 and processed for immunohistochemistry (original magnification, $\times 200$ ) with anti-heparanase antibody (A); H\&E staining (B); immunohistochemistry with antibodies directed against CD31 (C), plкB $\alpha(\mathbf{D})$, COX-2 (E), and cyclin D1 (G); and immunofluorescence with antibodies directed against pSTAT3 (yellow) (F). Arrows in $\mathbf{C}$ indicate CD31-positive microvessels. Cell nuclei were counterstained with DRAQ5 (blue); Scale bars: $25 \mu \mathrm{m}$. (A-E and G) Original magnification, $\times 200$. (H) TNF- $\alpha$ secretion by ex vivo-cultured punch biopsies harvested from the colon of untreated and DSS-treated WT (black bars) and Hpa Tg (gray bars) mice on day 80 of the experiment. ND, non-detectable. (I) Increased levels of Tnfa mRNA determined by qRTPCR in Hpa Tg (gray bars) versus WT (black bars) colon on day 80 of the experiment. Tnfa mRNA levels were normalized to actin mRNA $(n=5)$. (J) Microvessel counts in colons of $\mathrm{Hpa} \mathrm{Tg}$ (gray bars) and WT (black bars) mice $(n=6)$. (K) Number of cyclin D1-positive cells in colons of Hpa Tg (gray bars) and WT (black bars) mice $(n=6)$. ${ }^{\star} P<0.05,{ }^{\star \star \star} P<0.001$.

LPS in the absence or presence of recombinant active heparanase to recapitulate conditions that occur in UC (i.e., heparanase-rich environment and abundant microbial flora). Pretreatment with heparanase strongly sensitized macrophages to activation by LPS, as indicated by a 7-fold increase in TNF- $\alpha$ secretion (Figure 4D) and by a significant increase in mRNA of TNF- $\alpha$ as well as IL- 6 and IL-12p35 (Figure 4E), two additional macrophage-derived cytokines known to be induced by TLR4 signaling and tightly involved in the pathogenesis of UC (54). Notably, sensitization of macrophages to LPS by heparanase was dependent on its enzymatic activity, since 
pretreatment with heat-inactivated heparanase (iHpa) did not affect macrophage activation by LPS (Figure 4, D and E). These findings are in agreement with previous reports showing that extracellular HS in its intact form inhibits LPS-mediated TLR4 signaling and macrophage activation and that its removal relieves this inhibition (55). To confirm that heparanase activity is capable of decreasing cell surface HS in this system, we compared the bFGF binding capacity of mouse macrophage-like RAW264.7 cells untreated or treated with heparanase, as previously described (26), taking into account that HS functions as a low-affinity/high-capacity receptor for bFGF (56). Heparanase-treated and -untreated RAW264.7 cells were incubated with increasing concentrations of ${ }^{125} \mathrm{I}-\mathrm{bFGF}$, and their ability to bind bFGF was evaluated by measuring the radioactivity associated with the cells. Under the applied experimental conditions, bFGF binds primarily to HS (26). As demonstrated in Figure 4F, binding of ${ }^{125}$ I-bFGF to heparanase-treated cells was markedly decreased, indicating that heparanase reduces the amount of HS on the macrophage cell surface. Taken together, the above data suggest that upregulated heparanase enables enhanced activation of macrophages, reprogramming their response from resolution of inflammation to unresolved chronic colitis.

Although heparanase enzymatic activity appears to play a central role in this phenomenon, it should be noted that under certain experimental conditions heparanase may also exert enzymatic-independent effects, the best documented of which is induction of Akt/ PKB phosphorylation (3). In light of the importance of Akt/PKB signaling in macrophage function (57-59), we tested whether the effect of heparanase on Akt phosphorylation may be responsible (at least in part) for the observed sensitization of macrophages in our system. Applying immunoblotting with anti-phospho-Akt (pAkt) antibody, we compared activation levels of Akt in macrophages untreated or treated with heparanase in the absence or presence of LPS. Lack of increase in pAkt following treatment with heparanase alone, as opposed to 3.5 fold increase in pAkt levels detected in macrophages exposed to LPS in either the absence (in agreement with ref. 58) or presence of heparanase (data not shown) suggests that non-enzymatic activity (i.e., induction of Akt/PKB signaling) is less relevant in heparanase-mediated sensitization of macrophages. However, the contribution of additional, currently unknown nonenzymatic effects of heparanase could not be excluded.

Induction of heparanase expression by activated macrophages. In light of the ability of inflammatory cytokines to induce heparanase expression (60), it is plausible that activated macrophages represent an important source of cytokines capable of stimulating overexpression of epithelial heparanase in colitis. In support of this assumption, incubation of Colo205 colon carcinoma cells with medium conditioned by LPS-activated macrophages resulted in a more than 3-fold increase in heparanase levels compared with Colo205 cells that remained untreated or incubated with either LPS alone, or medium conditioned by resting macrophages (data not shown). Based on reports implicating TNF- $\alpha$ in upregulation of heparanase in endothelial cells (60), we hypothesized that macrophage-derived TNF- $\alpha$ is a likely mediator of heparanase induction in this system. In subsequent experiments, Colo205 cells were maintained untreated or treated with TNF- $\alpha$ for 24 hours and heparanase expression was assessed by real-time PCR, immunofluorescent staining, and activity assay. As shown in Figure 5, A-C, TNF- $\alpha$ treatment caused a marked increase in heparanase mRNA levels, protein content, and enzymatic activity. Similar results were obtained utilizing the Caco- 2 colon carcinoma cell line (data not shown). In addition, the ability of TNF- $\alpha$ to upregulate heparanase in normal colonic epithelium was demonstrated by increased heparanase expression in colonic explants (derived from healthy mouse colon) cultured ex vivo in the presence of TNF- $\alpha$ ( $15 \mathrm{ng} / \mathrm{ml}$; Figure 5, D and E), and by induction of heparanase in colonic epithelium of healthy mice following i.p. injection of TNF- $\alpha$ (Figure 5F). Next we tested the effect of the TNF- $\alpha$ antagonist etanercept, previously shown to inhibit bioactivity of murine TNF- $\alpha$ (61), on heparanase production in mouse colon during DSS colitis. For this purpose, mice receiving 5\% DSS in the drinking water for 7 days were injected i.p. with either vehicle (saline) alone or etanercept $(3 \mathrm{mg} / \mathrm{kg}$ body weight, twice a day, starting on experimental day 1 ). On experimental day 8 , mice were weighed and sacrificed, and heparanase expression was assessed by immunostaining and enzymatic activity determined in medium conditioned ex vivo by colonic explants harvested from etanercept-treated and -untreated mice. As shown in Supplemental Figure 6, A and B, etanercept treatment markedly reduced heparanase induction upon DSS challenge, further confirming the role of TNF- $\alpha$ in heparanase upregulation in vivo.

Role of macrophages in proteolytic activation of heparanase. During the course of DSS-induced colitis in WT mice, we observed not only an increase in total heparanase expression, but also augmented levels of proteolytically processed active heparanase (Figure 1, D-F). In accordance, increased levels of CatL mRNA and protein (Figure 1, $\mathrm{C}$ and D) were observed in extracts of mouse colonic tissues at corresponding time points. However, no notable CatL expression was detected by immunostaining in heparanase-overexpressing inflamed colonic epithelium during any stage of DSS colitis (Figure $1 G$ ). Instead, CatL-positive cells (primarily immunocytes) were accumulated in the stromal compartment of the colon during all stages of chronic colitis (Figure 1G). It has been previously shown that CatL plays an important pathophysiological role in colonic inflammation and that macrophages are the primary cellular source of inducible CatL expression in inflamed colon of UC patients and in acute DSS-induced mouse colitis (62). A different cellular source of heparanase (epithelial) and CatL (stroma/immunocytes) implies that proteolytic processing of heparanase by CatL takes place in the extracellular space. The secreted nature of heparanase in our system was demonstrated by the presence of heparanase enzymatic activity in medium conditioned by ex vivo-cultured punch biopsies harvested from the colon of DSS-treated versus untreated mice on day 59 of the experiment (Figure 1F). While several cell types may secrete inactive proforms of CatL, activated macrophages are unique in their ability to secrete mature CatL through a specific mechanism that stabilizes CatL and allows extracellular accumulation of the active enzyme (63). Altogether, these data led us to hypothesize that in chronic colitis, activated macrophages are decisively involved in proteolytic processing and activation of the latent proheparanase, providing a pool of extracellular active CatL. To test this hypothesis, we first applied double-immunofluorescent staining with antibodies directed against the macrophage marker F4/80 and CatL in mouse DSS colitis samples. As shown in Figure 6A, the majority of F4/80positive cells in WT colon specimens harvested on day 59 of DSS colitis were also positive for CatL, resembling the findings reported in inflamed mucosal tissue of UC patients (62). To test whether activated macrophages are capable of proteolytic processing and activation of pro-heparanase, we incubated purified $65-\mathrm{kDa}$ heparanase precursor with the conditioned medium of resting or LPS-stimulated mouse peritoneal macrophages, in the absence or presence of specific and irreversible CatL inhibitor and examined the resulting heparanase enzymatic activity. As shown in Figure 6B, incubation of 
A
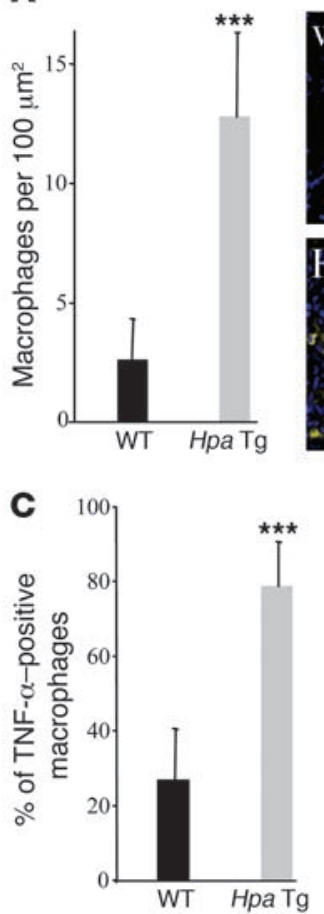

B
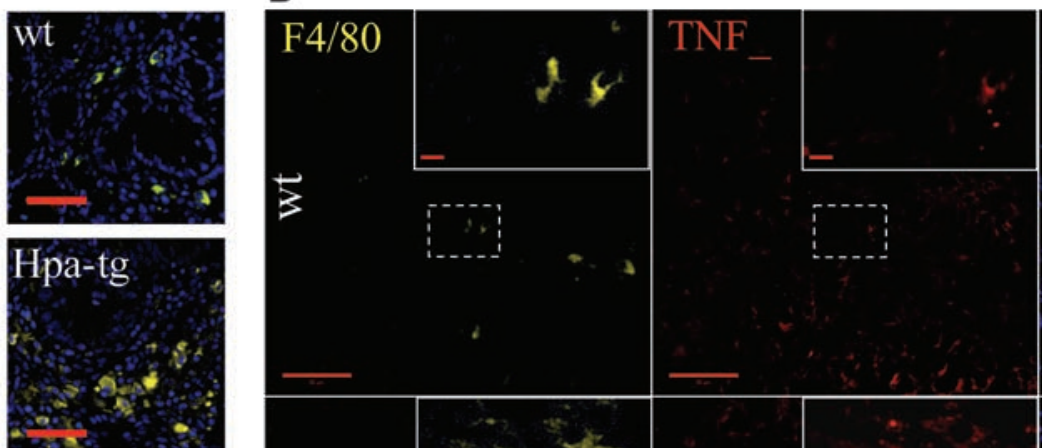

DRAQ5 F $4 / 80$ TNF $\alpha$ merged
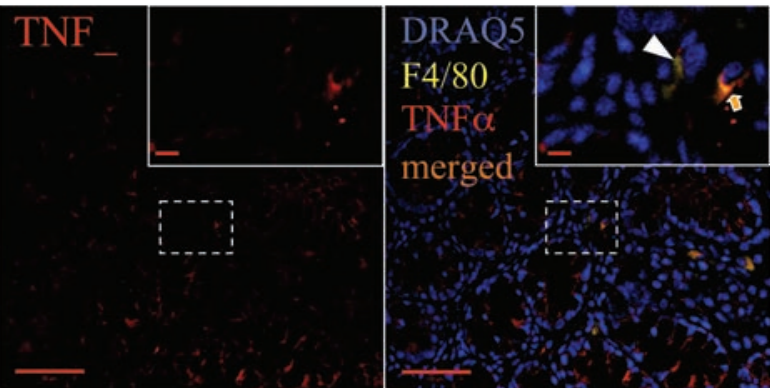

(r)
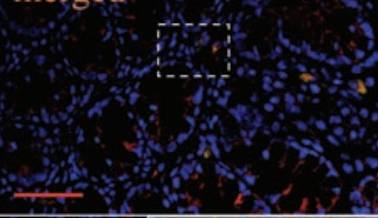

西

突
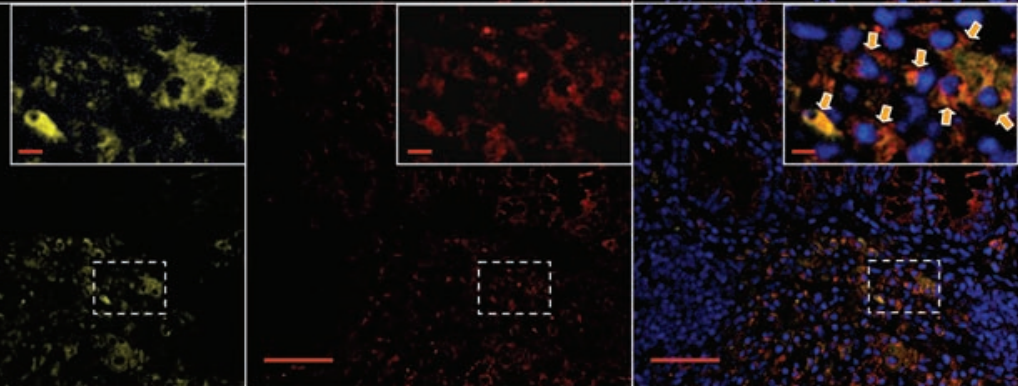

12

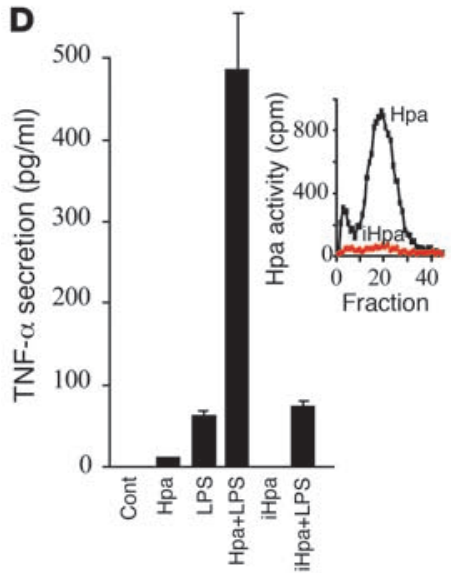

E
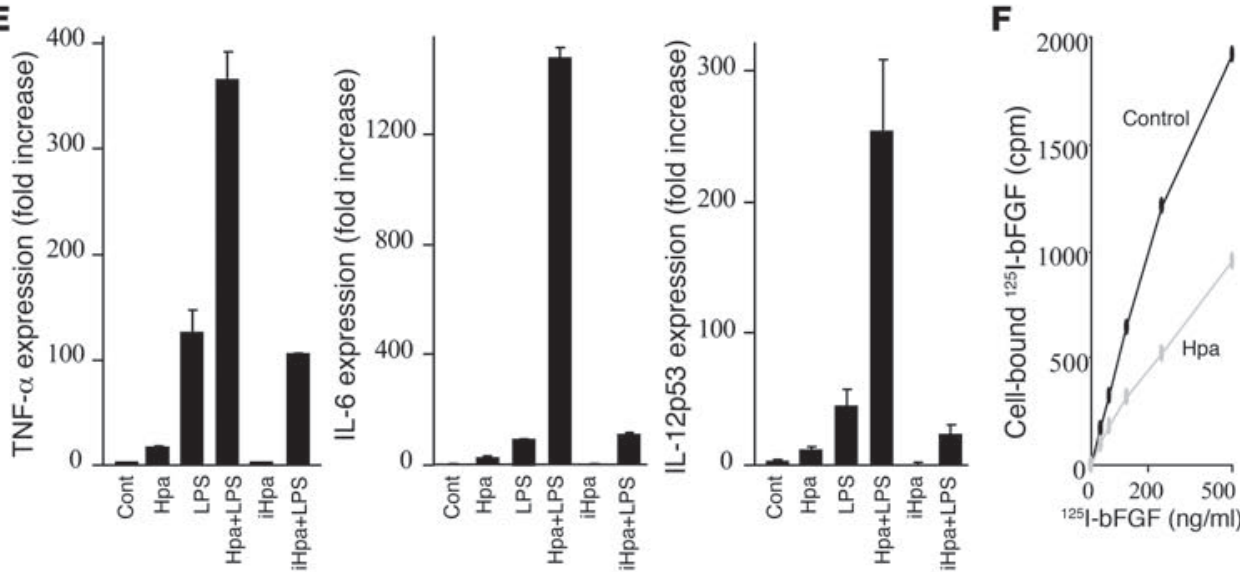

Figure 4

Effect of heparanase on macrophages. (A) Increased macrophage accumulation during chronic DSS colitis in Hpa Tg colon. Colonic tissue was obtained from Hpa Tg and WT mice on day 80 and stained with anti-F4/80 antibody. F4/80-positive macrophages were quantified per 100- $\mu \mathrm{m}^{2}$ microscopic field, based on 6 sections from 3 independent mice of each group. Inset: F4/80-positive macrophages (yellow) infiltrating WT (top) and Hpa $\mathrm{Tg}$ (bottom) colon. Scale bars: $50 \mu \mathrm{m}$. (B) Increased number of TNF- $\alpha$-expressing macrophages in $\mathrm{Hpa}$ Tg colon. Colonic tissue was processed for double immunofluorescent analysis with anti-F4/80 (yellow) and anti-TNF- $\alpha$ (red) antibodies. Cell nuclei were counterstained with DRAQ5 (blue). Scale bars: $50 \mu \mathrm{m}$. Insets: Enlarged images of the area delineated by dashed lines. Orange arrows indicate TNF- $\alpha-$ expressing macrophages; white arrowhead indicates TNF- $\alpha$-negative macrophage. Scale bars: $5 \mu \mathrm{m}$. (C) F4/80 and TNF- $\alpha$ double-positive cells (TNF- $\alpha$-expressing macrophages) were quantified per 100- $\mu \mathrm{m}^{2}$ microscopic field ( 6 sections from 3 independent mice), and the percentage of TNF- $\alpha-$ positive macrophages was calculated. (D and E) Heparanase sensitizes macrophages to LPS activation in vitro. Mouse peritoneal macrophages were untreated (Cont) or treated ( 2 hours, $37^{\circ} \mathrm{C}$ ) with active recombinant heparanase $(0.8 \mathrm{mg} / \mathrm{ml})$, LPS $(100 \mathrm{ng} / \mathrm{ml})$, heparanase followed by LPS (Hpa+LPS), heat-inactivated heparanase (iHpa) alone, or iHpa followed by LPS (iHpa+LPS). (D) TNF- $\alpha$ secretion was evaluated by ELISA. (E) TNF- $\alpha$, IL-6, and IL-12p35 expression was assessed by qRT-PCR. (F) Heparanase decreased HS content on macrophage cell surface. RAW264.7 macrophages were either untreated (Cont) or treated $\left(2\right.$ hours, $\left.37^{\circ} \mathrm{C}\right)$ with active heparanase, and HS content was assessed as described in Methods. ${ }^{* \star *} P<0.001$.

the $65-\mathrm{kDa}$ heparanase precursor with medium conditioned by resting macrophages resulted in little or no heparanase activity. By contrast, heparanase processing and activation became evident upon incubation of the $65-\mathrm{kDa}$ precursor with medium conditioned by
LPS-stimulated macrophages (Figure 6B). Moreover, the increase in heparanase activity was abolished in a dose-dependent manner in the presence of the specific irreversible CatL inhibitor (Figure 6B). Similar results were obtained when macrophages were activated with 
A
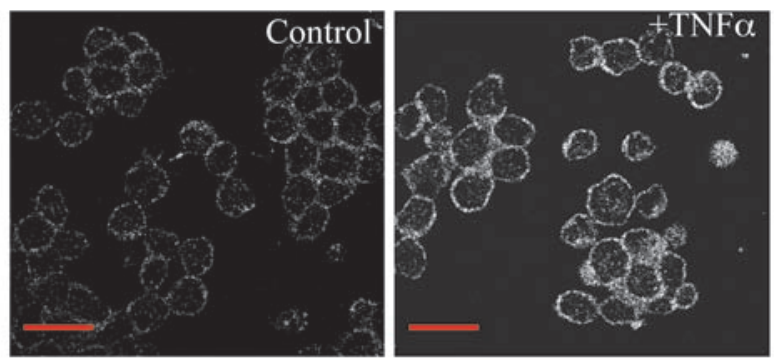

B

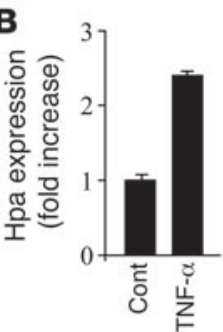

C
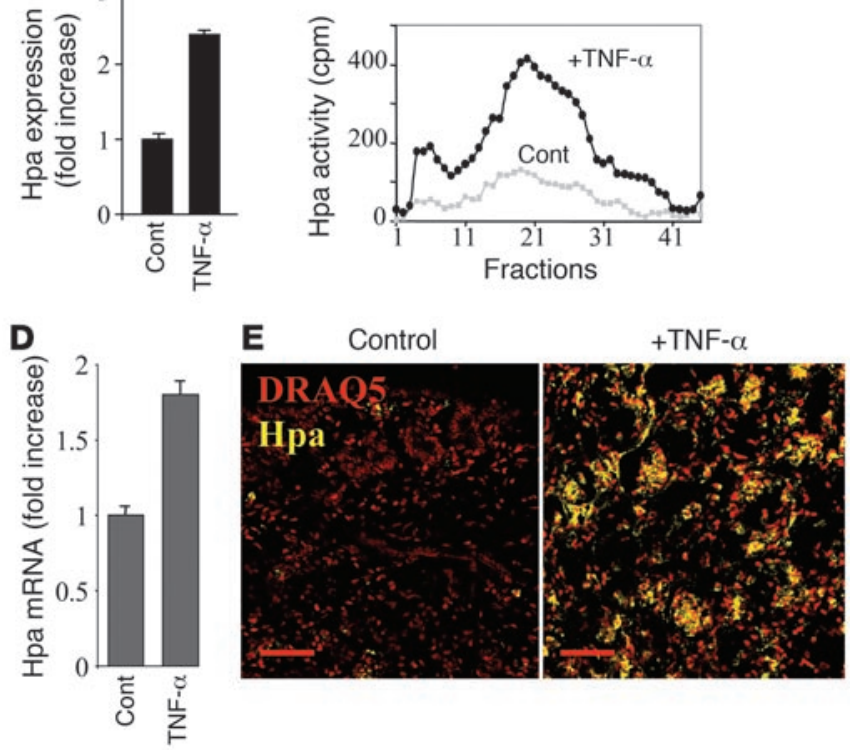

$\mathbf{F}$
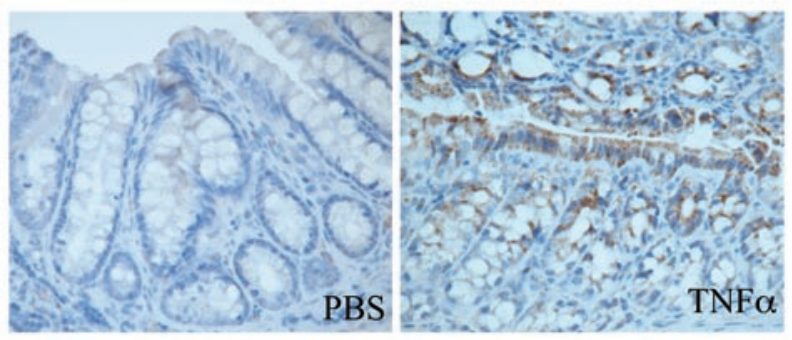

IFN- $\gamma$ instead of LPS (data not shown). Collectively, these findings suggest the occurrence of a vicious cycle through which heparanase stimulates macrophage activation, while the activated macrophages stimulate further production and activation of heparanase.

\section{Discussion}

Despite improved surveillance and therapy of IBD, the risk of colorectal cancer in the setting of ulcerative colitis remains substantial. Thus, more data about the identity of downstream effectors responsible for the cascade of molecular/cellular events linking UC and cancer are needed to properly address disease prevention and treatment. Significant progress has been made in deciphering the role of inflammatory cytokines (TNF- $\alpha$, IL-1 $\beta$, IL-6) and their downstream transcription factors (NF-kB, STAT3) in tumor-stimulating crosstalk between immune and epithelial cells $(18,20,38,39,44,45$, 61). Much less is known about the role of ECM-degrading enzymes in this crosstalk. Here we demonstrate, for what we believe is the first time, the functional importance of heparanase in modulating

\section{Figure 5}

TNF- $\alpha$ induces heparanase expression in Colo205 colonic carcinoma cells and in normal mouse colonic epithelium ex vivo and in vivo. (A-C) Colo205 cells were incubated (16 hours) in triplicate in the absence or presence of $15 \mathrm{ng} / \mathrm{ml}$ TNF- $\alpha$. Heparanase expression was assessed 16 hours later by (A) immunofluorescent staining (scale bars: $20 \mu \mathrm{m}$ ), (B) qRT-PCR determination of mRNA levels, and (C) enzymatic activity assay. ( $\mathbf{D}$ and $\mathbf{E})$ Heparanase induction in colonic explants treated with TNF- $\alpha$ ex vivo. Explants harvested from healthy mouse colon as described in Methods were cultured ex vivo for 16 hours in the absence and presence of TNF- $\alpha$ ( $15 \mathrm{ng} / \mathrm{ml})$. Heparanase expression was assessed 16 hours later by (D) qRT-PCR determination of mRNA levels and (E) immunofluorescent (yellow) staining (scale bars: $50 \mu \mathrm{m}$ ). (F) Induction of heparanase expression in mouse colonic epithelium following TNF- $\alpha$ administration in vivo. Colonic tissue specimens derived from healthy BALB/c mice injected i.p. with PBS or TNF- $\alpha(1 \mu \mathrm{g} / \mathrm{mouse}$, 24 hours) were stained with anti-heparanase antibody (brown staining). Note heparanase staining in colon epithelium derived from TNF- $\alpha-$ treated but not PBS-treated mice (original magnification, $\times 200$ ).

inflammatory responses and sustaining immune-epithelial crosstalk underlying the pathogenesis of chronic colitis-associated tumorigenesis. We identify epithelial cells as primary producers of heparanase in colonic inflammation (Figure 1). Moreover, epithelial heparanase induction appears to be not only a hallmark of chronic colitis, but at the same time an important mechanistic determinant linking inflammation and tumorigenesis. It is widely accepted that both tumor initiation and progression are profoundly affected by chronic inflammation (33). In this respect it is straightforward to assume that heparanase induction in the course of colitis contributes primarily to tumor progression (through enhanced angiogenesis, release of ECM-sequestered growth factors, generation of bioactive HS fragments, and creation of a growth-supportive microenvironment) $(3,4,9)$. Indeed, increased tumor burden observed in AOM/DSStreated Hpa Tg versus WT mice (Figure 2C) supports this assumption. However, the increase in tumor incidence in AOM/DSS-treated Hpa Tg mice (Figure 2C) and the formation of tumors following DSS treatment (without AOM) that occurred solely in Hpa Tg but not in WT mice (Figure 2, G and H), suggest causal involvement of heparanase in initiation of colitis-associated tumors. Both animal models and human studies show that persistence and severity of inflammatory processes directly affect tumor initiation in the colon. Thus, repeated administration of 9 cycles of DSS (instead of the standard 3-cycle schedule) in the absence of AOM caused colonic tumor formation in almost half of the treated mice (25), and a higher degree of inflammation was reported in colon biopsies of UC patients that developed cancer, as compared with those who did not develop cancer $(64,65)$. Our results reveal that heparanase actively shapes the tumor-inducing inflammatory environment by sustaining recruitment (Figure 4A and Supplemental Figure 5A) and continuous activation (Figure 4, B-E) of mucosal macrophages, eventually fostering colitis-associated tumorigenesis. In fact, macrophages are known to have a dual role in inflammation. In the scenario of inflammation resolution, macrophages perform phagocytosis and produce anti-inflammatory cytokines, thereby preventing inflammatory responses from lasting too long. However, if inflammation resolution is deregulated, macrophage response switches to the pattern of chronic inflammation. Macrophages dominate in chronic inflammatory foci and generate significant amounts of growth factors, cytokines and reactive oxygen species $(18,33)$. The increase in mucosal macrophage population is well documented in UC patients (46). Recruitment and activation 
A
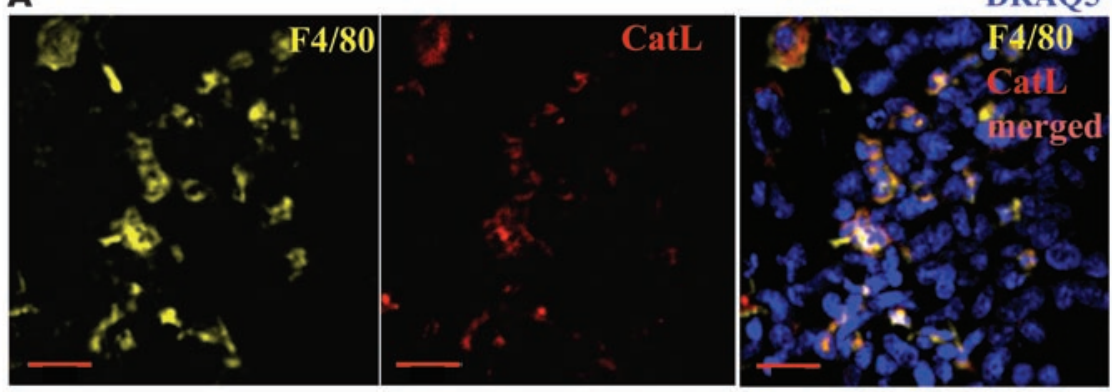

B

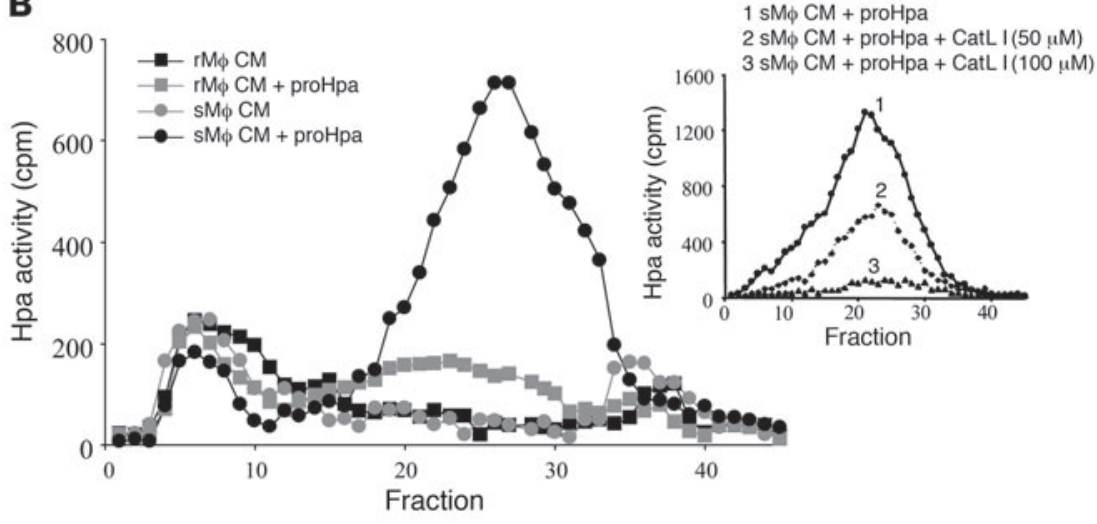

\section{Figure 6}

Role of macrophage-derived CatL in proteolytic activation of heparanase. (A) Colonic tissue was harvested on day 59 and processed for double immunofluorescent analysis applying anti-F4/80 and anti-CatL antibodies. Note that the vast majority of CatL-producing cells are F4/80-positive macrophages. (B) Proteolytic processing and activation of latent heparanase by macrophages. Purified $65-\mathrm{kDa}$ heparanase precursor (proHpa) was incubated with medium conditioned by resting $(\mathrm{rM} \phi)$ or LPS-stimulated $(\mathrm{sM} \phi)$ mouse peritoneal macrophages. Heparanase enzymatic activity was examined using sulfate-labeled ECM as substrate. Note lack of activity following incubation of the $65-\mathrm{kDa}$ precursor with medium conditioned by $\mathrm{rM} \phi$, as compared with readily detectable activity upon incubation with medium conditioned by $\mathrm{sM} \phi$. Inset: Proheparanase was incubated with medium conditioned by $\mathrm{SM} \phi$ in the absence or presence of increasing concentrations of specific CatL inhibitor I (compound Z-Phe-Phe-CH2F; Calbiochem catalog no. 421419). Heparanase enzymatic activity was examined using sulfatelabeled ECM as substrate. of macrophages within the intestinal mucosa play a key role in the pathogenesis of both human UC $(46,54)$ and murine DSS-induced colitis $(47,48)$. A large number of studies suggest that activated macrophages are candidate linking cells between inflammation and cancer $(33,49)$. For instance, the tumor-promoting cytokines IL-1, IL-6, and TNF- $\alpha(20,61)$ are produced mainly by activated macrophages and, along with macrophage-derived growth factors and reactive oxygen species, foster tumor initiation $(33,54)$. Given that one of the unique aspects of colorectal cancer development is the involvement of lumenal flora and TLR signaling $(52,53)$, the ability of heparanase to sensitize macrophages to LPS activation (Figure 4, D and E) is particularly important in light of the increased epithelial permeability to lumenal microbial products, characteristic of UC (32).

Consistent with the presence of continuously activated TNF- $\alpha-$ producing macrophages in heparanase-rich microenvironment,

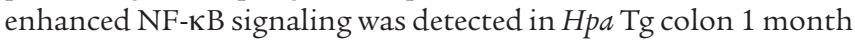
after cessation of the last DSS cycle (Figure 3D). In agreement with $\mathrm{NF}-\kappa \mathrm{B}$ activation, we found increased levels of several NF- $\kappa \mathrm{B}-$ dependent genes (i.e., COX-2, IL-1 $\beta$, IL-6 [Figure 3E and Supplemental Figure 4B], MIP-1 and MIP-2 [data not shown]) in Hpa Tg colonic tissue. Elevated levels of TNF- $\alpha$, in addition to increased expression of other STAT3-inducing cytokines (i.e., IL-6, IL-1 $\beta$; Supplemental Figure 4B), provide an explanation for the activation of STAT3 (the critical effector responsible for induction and progression of colitis-associated tumors; refs. 22, 38, 44, 45) in Hpa $\mathrm{Tg}$ colonic epithelium (Figure $3 \mathrm{~F}$ ).

On the other hand, we found that activated macrophages are capable of inducing heparanase expression in colonic epithelial cells (3-fold increase, data not shown), most likely through a TNF- $\alpha$ mediated mechanism (Figure 5). The early growth response 1 (EGR1) transcription factor may be an important mediator of heparanase induction in this system. EGR1 is induced by TNF- $\alpha$ in many cell types (including colon; ref. 66), and has been shown to mediate TNF-stimulated expression of numerous genes. EGR1 is a powerful inducer of heparanase in colonic tumor cells (ref. 67 and Supplemental Figure 7C). We found a strong increase in EGR1 expression by the colon mucosa on days $10(P<0.001), 59$, and 80 $(P<0.01)$ of the DSS colitis model (Supplemental Figure 7A), in agreement with findings previously reported in IBD patients, in which TNF- $\alpha$ was shown to stimulate EGR1 expression (66). Accordingly, treatment with TNF- $\alpha$ caused a 5.5-fold increase in EGR1 expression in Colo205 cells (Supplemental Figure 7B). Moreover, ChIP analysis revealed a 3.5-fold increase in in vivo occupancy of the heparanase promoter by EGR1 in colonic tissue derived from DSS-treated as compared with untreated mice (Supplemental Figure 7, D and E), further validating the involvement of EGR1 in induction of heparanase gene expression in DSS colitis.

In addition, due to their unique ability to secrete mature CatL and allow extracellular accumulation of the active enzyme (63), activated macrophages appear to be responsible for proteolytic activation of latent proheparanase in colitis (Figure 6). Thus, macrophages not only represent a cellular target for heparanase action, but also decisively regulate heparanase in chronic colitis, at both the transcriptional and the posttranslational levels. Collectively, our results suggest that heparanase generates a self-sustaining connection between chronic colitis and tumorigenesis (Figure 7): macrophages (activated by influx of the luminal flora [Figure 7, part i] due to defects in the epithelial barrier function characteristic of UC; ref. 32) represent, among other cells, important source of TNF- $\alpha$ and stimulate production of heparanase by the colon epithelium (Figure 7 , part ii). The secreted $65-\mathrm{kDa}$ latent heparanase is processed into its active $(8+50 \mathrm{kDa})$ form by CatL, supplied by the activated macrophages (Figure 7, part iii). Enzymatically active heparanase sensitizes macrophages to further activation by microbial flora, 


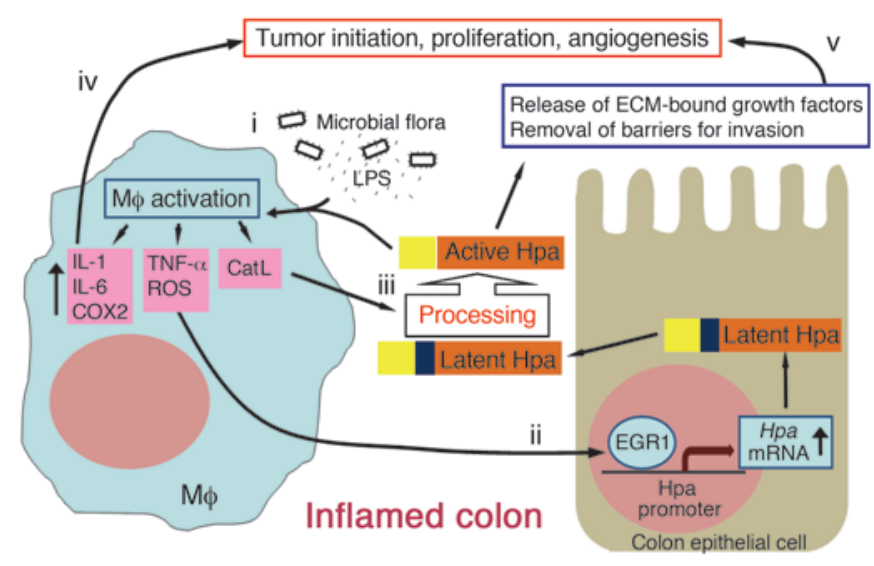

Figure 7

A model of heparanase-driven vicious cycle that powers colitis and the associated tumorigenesis. (i) Increased levels of TNF- $\alpha$ (secreted, among other cells, by macrophages activated by excessive exposure to the luminal flora, due to epithelial barrier function defects characteristic for UC) induce heparanase expression in colon epithelium via an EGR1dependent mechanism (ii). (iii) The secreted $65-\mathrm{kDa}$ latent heparanase is processed into its enzymatically active $(8+50 \mathrm{kDa})$ form by CatL (which is supplied by the activated macrophages), and in turn sensitizes macrophages to further activation by luminal flora, thus preventing inflammation resolution, switching macrophage responses to the chronic inflammation pattern and creating tumor-inducing inflammatory environment (iv). In addition, heparanase promotes tumor progression via stimulation of angiogenesis, release of ECM-bound growth factors and bioactive HS fragments, and removal of extracellular barriers for invasion (v).

thus preventing inflammation resolution, switching macrophage responses to the chronic inflammation pattern and creating tumorinducing inflammatory environment (Figure 7, part iv). In addition, high heparanase levels support tumor progression via stimulation of angiogenesis, release of ECM-bound growth factors and bioactive HS fragments, and removal of extracellular barriers for invasion (Figure 7, part v). The newly identified heparanase-powered vicious cycle may explain a yet poorly understood "multiplier effect" in IBD inflammation, in which even a small elevation in initiating inflammatory stimuli gives rise to large increases in downstream cytokines (68). Although the complex puzzle of mechanisms underlying the association between inflammation and cancer is still far from being fully understood, our study highlights one of the previously missing links in this intriguing puzzle and suggests that strategies that disrupt this link may be of clinical benefit to UC patients.

\section{Methods}

Experimental design. Male BALB/c mice were purchased from Harlan Laboratories. Hpa $\mathrm{Tg}$ mice in which transgenic heparanase is driven by a constitutive $\beta$-actin promoter (26) in a BALB/c genetic background were bred at the animal facility of the Hadassah-Hebrew University Medical Center. All mice were kept under conventional pathogen-free conditions, and all experiments were performed with approval from the Hebrew University IACUC. Colitis was induced in 10- to 12-week-old mice by administration of 5\% (wt/vol) DSS (Mr 36-40 kDa; MP Biomedicals) in the drinking water for 7 days, followed by 2 -week consumption of regular water. This cycle was repeated 3 times (Figure 1B). Where indicated, i.p. injection of AOM (Sigma-Aldrich) $(12.5 \mathrm{mg} / \mathrm{kg})$ was given to mice 7 days prior to the first DSS administration (Figure 1B). The disease severity was evaluated as described (69) by scoring 3 major clinical signs (weight loss, diarrhea, and rectal bleeding). Animals were sacrificed on experimental days 10, 59, 80, or 110 ( $n \geq 9$ at each time point) and their colons isolated and processed for histological examination and immunostaining or snap-frozen for RNA/ protein isolation. Where indicated in the figure legends, i.p. injections of mouse recombinant TNF- $\alpha$ (Peprotech) $(1 \mu \mathrm{g} /$ mouse) were given to mice 24 hours prior to sacrifice, as described in ref. 70 . In some experiments, mice were injected i.p. with the TNF- $\alpha$ antagonist etanercept (Wyeth Pharmaceuticals; $2.5 \mathrm{mg} / \mathrm{kg}$ body weight, twice a day for 8 days).

Punch biopsies. Mouse colons were flushed 3 times with PBS containing antibiotics and opened along a longitudinal axis. Thereafter, $4-\mathrm{mm}^{2}$ punch biopsies were obtained and incubated for 24 hours in RPMI-1640 medium supplemented with antibiotics. Supernatants were collected and kept in $-20^{\circ} \mathrm{C}$ until assessed for heparanase enzymatic activity and cytokine expression (using ELISA or antibody array).

Antibody array. Qualitative measurement of cytokine content in medium conditioned by colonic explants was performed using the RayBio Mouse Cytokine Antibody Array (G series 2) (32) according to the manufacturer's manual. The signals were detected using streptavidin-conjugated fluorescent $\mathrm{Cy} 3$ dye, according to the manufacturer's manual, and digitized using the Genepix 4000B Array Scanner (Axon Instruments).

Histopathological analysis. Mouse colon was rolled up, fixed in $4 \%$ buffered formalin, and embedded in paraffin. Serial tissue sections ( $5 \mu \mathrm{m}$ thick) were stained with $\mathrm{H} \& \mathrm{E}$ and visualized with a Zeiss axioscope microscope. Inflammatory and neoplastic lesions were scored in a blinded fashion by 2 expert pathologists. The area of each neoplastic lesion was determined using Scion Image software. Colon biopsy specimens from healthy individuals and patients with UC were provided by the Department of Pathology, Hadassah Medical Center. The use of these specimens was approved by the Institutional Human Subjects Research Ethical Committee as exempt from IRB review because the study does not meet Common Rule Section 101(b) criteria for "research involving human subjects." Tissue samples were de-identified and were impossible to trace back to the patient.

Cell culture. Colo205 and Caco-2 human colon carcinoma cells were grown in DMEM supplemented with $1 \mathrm{mM}$ glutamine, $50 \mu \mathrm{g} / \mathrm{ml}$ streptomycin, $50 \mathrm{U} / \mathrm{ml}$ penicillin, and $10 \%$ fetal calf serum (Biological Industries) at $37^{\circ} \mathrm{C}$ and $8 \% \mathrm{CO}_{2}$. At $60 \%-80 \%$ confluence, cells were maintained for 24 hours in serum-free medium and then remained untreated or were treated with TNF- $\alpha$ or macrophage-conditioned medium. Cells were then lysed and processed for RNA isolation and assessment of heparanase enzymatic activity. In some experiments, cells were cultured on glass coverslips (12 mm; Carolina Biological Supply Company), fixed with 100\% ice-cold methanol, and processed for immunofluorescent staining.

Isolation of murine peritoneal macrophages. Ten-week-old male C57BL/6 mice were injected i.p. with $1.5 \mathrm{ml}$ of $4 \%$ thioglycollate (BD Biosciences) and sacrificed 3 days later. PBS $(2.5 \mathrm{ml} \times 4)$ was injected into the peritoneal cavity, and the peritoneal lavage was pooled and centrifuged at $200 \mathrm{~g}$ for 5 minutes. The pellet was resuspended in DMEM supplemented with $1 \mathrm{mM}$ glutamine, $50 \mu \mathrm{g} / \mathrm{ml}$ streptomycin, $50 \mathrm{U} / \mathrm{ml}$ penicillin, and $10 \%$ fetal calf serum, and the cells were plated for 1 hour and then washed 3 times with DMEM to remove non-adherent cells. This procedure yielded cells that were more than $95 \%$ positive for $\mathrm{F} 4 / 80$.

Antibodies. Immunoblot analysis and immunostaining were carried out with the following antibodies: anti-cyclin D1 (Thermo Scientific), anti-Ki-67 (Thermo Scientific), anti-heparanase, polyclonal antibody \#733 raised in rabbits against a 15 -amino acid peptide ${ }^{158}$ KKFKNSTYSRSSVD ${ }^{171}$ that maps at the $\mathrm{N}$ terminus of the $50-\mathrm{kDa}$ heparanase subunit (11), monoclonal antibody $01385-126$ recognizing both the 50-kDa subunit and the 65-kDa proheparanase (refs. 10, 71; provided by P. Kussie (ImClone Systems Inc.), anti-CatL (R\&D Systems), anti-COX2 (Cayman), anti-CD31 
(Biocare Medical), anti- $\beta$-catenin (Sigma-Aldrich), anti-myeloperoxidase (Thermo Scientific), anti-pIкB $\alpha$, anti-phospho-NF-кB p65, anti-pStat3, anti-cleaved caspase-3 (Cell Signaling), anti-TNF- $\alpha$ (R\&D Systems), antiPCNA (Santa Cruz Biotechnologies Inc.), and anti-F4/80 (Serotec).

Immunohistochemistry. Paraffin-embedded slides were deparaffinized and incubated in $3 \% \mathrm{H}_{2} \mathrm{O}_{2}$. Antigen unmasking was carried out by heating ( $20 \mathrm{~min}$ utes) in a microwave oven in $10 \mathrm{mM}$ Tris buffer containing $1 \mathrm{mM}$ EDTA. Slides were incubated with primary antibodies diluted in CAS-Block (Invitrogen) or with CAS-Block alone, as a control. Appropriate secondary antibodies (Nichirei) were then added and slides incubated at room temperature for $30 \mathrm{~min}$ utes. Mousestain kit (Nichirei) was used when primary mouse antibodies were applied to stain mouse tissues. Color was developed using the DAB substrate kit (Thermo Scientific) or Zymed AEC substrate kit (Zymed Laboratories), followed by counterstaining with Mayer's hematoxylin. Controls without addition of primary antibody showed low or no background staining in all cases.

Immunofluorescence. For double immunofluorescence analysis, sections were incubated with a combination of anti-F4/80 (Serotec) with anti-TNF- $\alpha$ (R\&D Systems), anti-CatL (R\&D Systems), or anti-pIкB $\alpha$ antibodies. DyLight 488 donkey anti-rat and DyLight 549 donkey anti-goat and antimouse (Jackson Laboratories) antibodies were used as secondary antibodies. Nuclear staining was performed with 1,5-bis\{[2-(di-methylamino) ethyl]amino\}-4,8-dihydroxyanthracene-9, 10-dione (DRAQ5) (Cell Signaling). Images were captured using a Zeiss LSM 5 Confocal microscope and analyzed with Zen software (Carl Zeiss).

Immunoblotting. Colonic tissue samples were homogenized in lysis buffer containing $1 \%$ Triton X-100, $150 \mathrm{mM} \mathrm{NaCl}, 20 \mathrm{mM}$ Tris- $\mathrm{HCl}$, pH 7.5, supplemented with a mixture of protease inhibitors (Sigma-Aldrich). Equal protein aliquots were subjected to SDS-PAGE (10\% acrylamide) under reducing conditions, and proteins were transferred to a polyvinylidene difluoride membrane (Millipore). Membranes were blocked with $1 \%$ skim milk for 1 hour at room temperature and probed with the appropriate antibody, followed by horseradish peroxidase-conjugated secondary antibody (KPL) and a chemiluminescent substrate (iNtron Biotechnology). Band intensity was quantified by densitometry analysis using Scion image software.

Determination of vessel density. Blood vessels were visualized by staining with rat anti-mouse CD31 (Biocare Medical) antibody. The number of blood vessels was counted in 10 randomly selected high-power microscopic fields (HPFs, magnification $\times 200$ ) of each colon (4 colons/group), and the mean value $\pm \mathrm{SD}$ was determined.

Heparanase activity assay. For measurements of heparanase enzymatic activity, conditioned medium or cell lysates were incubated (16-36 hours, $37^{\circ} \mathrm{C}$, pH 6.2) on dishes coated with sulfate-labeled ECM, prepared as previously described $(7,72)$. Sulfate-labeled material released into the incubation medium was analyzed by gel filtration on a Sepharose $6 \mathrm{~B}$ column $(7,72)$. Nearly intact heparan sulfate proteoglycans are eluted just after the void volume (peak I, $\mathrm{K}_{\mathrm{av}}[\mathrm{Ve}-\mathrm{Vo} / \mathrm{Vt}-\mathrm{Vo}]<0.2$, fractions 1-10) and HS degradation fragments are eluted later with $0.5<\mathrm{K}_{\mathrm{av}}<0.8$ (peak II, fractions 15-35) $(7,72)$. These fragments were shown to be degradation products of HS, as they were 5- to 6-fold smaller than intact HS side chains, resistant to further digestion with papain and chondroitinase $\mathrm{ABC}$, and susceptible to deamination by nitrous acid (72). Each experiment was performed at least 3 times, and the variation in elution positions ( $K_{\mathrm{av}}$ values) did not exceed $\pm 15 \%$.

Analysis of gene expression by qRT-PCR. Total RNA was isolated from snapfrozen tissue samples using TRIzol (Invitrogen), according to the manu- facturer's instructions, and quantified by spectrophotometry. After oligo (dT)-primed reverse transcription of $500 \mathrm{ng}$ total RNA, the resulting singlestranded cDNA was amplified using qRT-PCR analysis with an automated rotor gene system RG-3000A (Corbett Research). The PCR reaction mix (20 $\mu \mathrm{l}$ ) was composed of $10 \mu \mathrm{l}$ QPCR SYBR Master Mix (Finnzymes), $5 \mu \mathrm{l}$ of diluted cDNA (each sample in a sextuplicate), and a final concentration of $0.3 \mu \mathrm{M}$ of each primer. PCR conditions were as follows: an initial denaturation step at $95^{\circ} \mathrm{C}$ for 10 minutes, 40 cycles of denaturation at $94^{\circ} \mathrm{C}$ for 15 seconds, hybridization at $57^{\circ} \mathrm{C}$ for 30 seconds, and elongation at $72^{\circ} \mathrm{C}$ for 30 seconds. Actin primers were used as an internal standard. The following primers were used: mouse CatL sense: $5^{\prime}$-GTGGACTGTTCTCACGCTCA$3^{\prime}$, antisense: 5'-TATCCACGAACCCTGTGTCA-3'; mouse COX-2 sense: 5'-GGGTGTCCCTTCACTTCTTTCA-3', antisense: 5'-TGGGAGGCACTTGCATTGA-3'; mouse iNOS sense: 5'-CAGCTGGGCTGTACAAACCTT-3', antisense: $5^{\prime}$-CATTGGAAGTGAAGCGTTTCG-3'; mouse $\beta$-actin sense: 5'-ATGCTCCCCGGGCTGTAT-3', antisense: 5'-CATAGGAGTCCTTCTGACCCATTC-3'; mouse TNF- $\alpha$ sense: 5'-CATCTTCTCAAAATTCGAGTGACAA-3', antisense: 5'-TGGGAGTAGACAAGGTACAACCC-3'; mouse IL-6 sense: 5'-CTGCAAGAGACTTCCATCCAGTT-3', antisense: 5'-GAAGTAGGGAAGGCCGTGG-3'; mouse IL-12p35 sense: 5'-CTTAGCCAGTCCCGAAACCT-3', antisense: 5'-TTGGTCCCGTGTGATGTCT-3'; mouse heparanase sense: $5^{\prime}$-ACTTGAAGGTACCGCCTCCG-3', antisense: 5'-GAAGCTCTGGAACTCGGCAA-3'

TNF- $\alpha$ ELISA. TNF- $\alpha$ levels were assayed using the ELISA MAX mouse TNF- $\alpha$ kit (Biolegend).

Assessment of cell surface HS content by measuring bFGF binding capacity. RAW264.7 cells were cultured in DMEM medium supplemented with $10 \%$ FCS. Confluent cells, untreated or pre-treated with recombinant heparanase $\left(15 \mu \mathrm{g} / \mathrm{ml}, 2\right.$ hours, $\left.37^{\circ} \mathrm{C}\right)$ were incubated $\left(1\right.$ hour, $\left.4^{\circ} \mathrm{C}\right)$ with increasing concentrations ( $0-500 \mathrm{ng} / \mathrm{ml})$ of ${ }^{125} \mathrm{I}-\mathrm{bFGF}(2.3 \mu \mathrm{Ci} / \mathrm{ng}$; Amersham Biosciences $)$ in triplicate in $35-\mathrm{mm}$ dishes in $1 \mathrm{ml}$ serum-free RPMI medium containing $0.5 \%$ BSA. The cells were washed 3 times and solubilized in $1 \mathrm{~N} \mathrm{NaOH}$, and the radioactivity of the cell pellets was counted in a $\gamma$-counter. Each data point was calculated as the mean of quadriplicate cultures; the variation between different determinations did not exceed $\pm 10 \%$ of the mean.

Statistics. Data were analyzed by unpaired $t$ test, $P$ values less than 0.05 were considered statistically significant. Results are presented as mean $\pm \mathrm{SD}$.

\section{Acknowledgments}

This work was supported by grants from the Israel Science Foundation (grant 593/10), the National Cancer Institute (NIH grant RO1-CA106456-06), the German-Israel Research Foundation (GIF), the Cooperation Program in Cancer Research of the Deutsches Krebsforschungszentrum and Israel's Ministry of Science, and the Israel Cancer Research Fund (ICRF). I. Vlodavsky is a Research Professor at the ICRF.

Received for publication May 23, 2010, and accepted in revised form January 26, 2011.

Address correspondence to: Michael Elkin, Tumor Biology Research Unit, Department of Oncology, Hadassah-Hebrew University Medical Center, Jerusalem 91120, Israel. Phone: 972.2.6776782; Fax: 972.2.6422794; E-mail: melkin@hadassah.org.il.
1. Iozzo RV. Heparan sulfate proteoglycans: intricate molecules with intriguing functions. J Clin Invest. 2001;108(2):165-167

2. Vlodavsky I, Bar-Shavit R, Ishai-Michaeli R, Bashkin P, Fuks Z. Extracellular sequestration and release of fibroblast growth factor: a regulatory mechanism? Trends Biochem Sci. 1991;16(7):268-271.
3. Vlodavsky I, et al. Heparanase: one molecule with multiple functions in cancer progression. Connect Tissue Res. 2008;49(3):207-210.

4. Elkin $\mathrm{M}$, et al. Heparanase as mediator of angiogenesis: mode of action. FASEB J. 2001;15(9):1661-1663.

5. Kato $\mathrm{M}$, et al. Physiological degradation converts the soluble syndecan- 1 ectodomain from an inhibi- tor to a potent activator of FGF-2. Nat Med. 1998; 4(6):691-697.

6. Edovitsky E, Elkin M, Zcharia E, Peretz T, Vlodavsky I. Heparanase gene silencing, tumor invasiveness, angiogenesis, and metastasis. J Natl Cancer Inst. 2004; 96(16):1219-1230.

7. Vlodavsky I, et al. Mammalian heparanase: gene 
cloning, expression and function in tumor progression and metastasis. Nat Med. 1999;5(7):793-802.

8. Parish CR, Freeman C, Hulett MD. Heparanase: a key enzyme involved in cell invasion. Biochim Biophys Acta. 2001;1471(3):M99-M108.

9. Yang Y, et al. Heparanase enhances syndecan-1 shedding: a novel mechanism for stimulation of tumor growth and metastasis. J Biol Chem. 2007; 282(18):13326-13333.

10. Abboud-Jarrous G, et al. Cathepsin L is responsible for processing and activation of proheparanase through multiple cleavages of a linker segment. J Biol Chem. 2008;283(26):18167-18176.

11. Doviner V, et al. Spatial and temporal heparanase expression in colon mucosa throughout the adenoma-carcinoma sequence. Mod Pathol. 2006; 19(6):878-888

12. Friedmann Y, et al. Expression of heparanase in normal, dysplastic, and neoplastic human colonic mucosa and stroma: evidence for its role in colonic tumorigenesis. Am J Pathol. 2000;157(4):1167-1175.

13. Naomoto Y, Takaoka M, Okawa T, Nobuhisa T, Gunduz M, Tanaka N. The role of heparanase in gastrointestinal cancer (Review). Oncol Rep. 2005;14(1):3-8.

14. Nobuhisa T, et al. Heparanase expression correlates with malignant potential in human colon cancer. J Cancer Res Clin Oncol. 2005;131(4):229-237.

15. Vlodavsky I, et al. Expression of heparanase by platelets and circulating cells of the immune system: possible involvement in diapedesis and extravasation. Invasion Metastasis. 1992;12(2):112-127.

16. Waterman M, Ben-Izhak O, Eliakim R, Groisman G, Vlodavsky I, Ilan N. Heparanase upregulation by colonic epithelium in inflammatory bowel disease. Mod Pathol. 2007;20(1):8-14.

17. Clevers H. Colon cancer--understanding how NSAIDs work. N Engl J Med. 2006;354(7):761-763.

18. Karin M, Greten FR. NF-kappaB: linking inflammation and immunity to cancer development and progression. Nat Rev Immunol. 2005;5(10):749-759.

19. Okayasu I, Ohkusa T, Kajiura K, Kanno J, Sakamoto S. Promotion of colorectal neoplasia in experimental murine ulcerative colitis. Gut. 1996;39(1):87-92.

20. Greten FR, et al. IKKbeta links inflammation and tumorigenesis in a mouse model of colitis-associated cancer. Cell. 2004;118(3):285-296

21. Agoff SN, et al. The role of cyclooxygenase 2 in ulcerative colitis-associated neoplasia. Am J Pathol. 2000;157(3):737-745

22. Yu H, Pardoll D, Jove R. STATs in cancer inflammation and immunity: a leading role for STAT3. Nat Rev Cancer. 2009;9(11):798-809.

23. Sato T, et al. Heparanase expression in human colorectal cancer and its relationship to tumor angiogenesis, hematogenous metastasis, and prognosis. J Surg Oncol. 2004;87(4):174-181.

24. Okayasu I, Hatakeyama S, Yamada M, Ohkusa T, Inagaki Y, Nakaya R. A novel method in the induction of reliable experimental acute and chronic ulcerative colitis in mice. Gastroenterology. 1990;98(3):694-702.

25. Okayasu I, Yamada M, Mikami T, Yoshida T, Kanno J, Ohkusa T. Dysplasia and carcinoma development in a repeated dextran sulfate sodiuminduced colitis model. J Gastroenterol Hepatol. 2002; 17(10):1078-1083.

26. Zcharia E, et al. Transgenic expression of mammalian heparanase uncovers physiological functions of heparan sulfate in tissue morphogenesis, vascularization, and feeding behavior. FASEB J. 2004; $18(2): 252-263$

27. Zcharia E, et al. Heparanase accelerates wound angiogenesis and wound healing in mouse and rat models. FASEB J. 2005;19(2):211-221.

28. Kram V, et al. Heparanase is expressed in osteoblastic cells and stimulates bone formation and bone mass. J Cell Physiol. 2006;207(3):784-792.

29. van den Hoven MJ, et al. Increased expression of heparanase in overt diabetic nephropathy. Kidney
Int. 2006;70(12):2100-2108.

30. Baker AB, et al. Heparanase alters arterial structure, mechanics, and repair following endovascular stenting in mice. Circ Res. 2009;104(3):380-387.

31. Li JP, et al. In vivo fragmentation of heparan sulfate by heparanase overexpression renders mice resistant to amyloid protein A amyloidosis. Proc Natl Acad Sci U S A. 2005;102(18):6473-6477.

32. Kumar V, Abbas A, Fausto N, eds. Robbins and Cotran Pathologic Basis of Disease. 7th ed. Burlington, Massachusetts, USA: Elsevier Saunders; 2005.

33. Coussens LM, Werb Z. Inflammation and cancer. Nature. 2002;420(6917):860-867.

34. Danese $S$, et al. Angiogenesis as a novel component of inflammatory bowel disease pathogenesis. Gastroenterology. 2006;130(7):2060-2073.

35. Danese S, et al. Angiogenesis blockade as a new therapeutic approach to experimental colitis. Gut. 2007;56(6):855-862.

36. Pahl HL. Activators and target genes of Rel/NFkappaB transcription factors. Oncogene. 1999; 18(49):6853-6866.

37. Wang D, Dubois RN. The role of COX-2 in intestinal inflammation and colorectal cancer. Oncogene. 2010;29(6):781-788.

38. Danese S, Mantovani A. Inflammatory bowel disease and intestinal cancer: a paradigm of the YinYang interplay between inflammation and cancer. Oncogene. 2010;29(23):3313-3323.

39. Becker C, et al. IL-6 signaling promotes tumor growth in colorectal cancer. Cell Cycle. 2005;4(2):217-220.

40. Banks C, Bateman A, Payne R, Johnson P, Sheron N. Chemokine expression in IBD. Mucosal chemokine expression is unselectively increased in both ulcerative colitis and Crohn's disease. J Pathol. 2003; 199(1):28-35

41. Vainer B, Nielsen OH, Horn T. Expression of E-selectin, sialyl Lewis $\mathrm{X}$, and macrophage inflammatory protein-1alpha by colonic epithelial cells in ulcerative colitis. Dig Dis Sci. 1998;43(3):596-608.

42. Bollrath J, et al. gp130-mediated Stat3 activation in enterocytes regulates cell survival and cell-cycle progression during colitis-associated tumorigenesis. Cancer Cell. 2009;15(2):91-102.

43. Grivennikov S, et al. IL- 6 and Stat 3 are required for survival of intestinal epithelial cells and development of colitis-associated cancer. Cancer Cell. 2009; 15(2):103-113

44. Bollrath J, Greten FR. IKK/NF-kappaB and STAT3 pathways: central signalling hubs in inflammation-mediated tumour promotion and metastasis. EMBO Rep. 2009;10(12):1314-1319.

45. Jarnicki A, Putoczki T, Ernst M. Stat3: linking inflammation to epithelial cancer - more than a "gut" feeling? Cell Div. 2010;5:14.

46. Mahida YR. The key role of macrophages in the immunopathogenesis of inflammatory bowel disease. Inflamm Bowel Dis. 2000;6(1):21-33.

47. Elson CO, Sartor RB, Tennyson GS, Riddell RH. Experimental models of inflammatory bowel disease. Gastroenterology. 1995;109(4):1344-1367.

48. Krieglstein CF, et al. Collagen-binding integrin alpha1 beta1 regulates intestinal inflammation in experimental colitis. J Clin Invest. 2002;110(12):1773-1782.

49. Pollard JW. Tumour-educated macrophages promote tumour progression and metastasis. Nat Rev Cancer. 2004;4(1):71-78

50. Starkey PM, Turley L, Gordon S. The mouse macrophage-specific glycoprotein defined by monoclonal antibody F4/80: characterization, biosynthesis and demonstration of a rat analogue. Immunology. 1987;60(1):117-122.

51. Poltorak A, et al. Defective LPS signaling in C3H/ $\mathrm{HeJ}$ and $\mathrm{C} 57 \mathrm{BL} / 10 \mathrm{ScCr}$ mice: mutations in Tlr4 gene. Science. 1998;282(5396):2085-2088.

52. Fukata M, et al. Toll-like receptor-4 promotes the development of colitis-associated colorectal tumors. Gastroenterology. 2007;133(6):1869-1881.
53. Fukata M, et al. Innate immune signaling by Tolllike receptor-4 (TLR4) shapes the inflammatory microenvironment in colitis-associated tumors. Inflamm Bowel Dis. 2009;15(7):997-1006.

54. Sanchez-Munoz F, Dominguez-Lopez A, YamamotoFurusho JK. Role of cytokines in inflammatory bowel disease. World J Gastroenterol. 2008;14(27):4280-4288.

55. Brunn GJ, Bungum MK, Johnson GB, Platt JL. Conditional signaling by Toll-like receptor 4. FASEB J. 2005;19(7):872-874.

56. Miao HQ, Ornitz DM, Aingorn E, Ben-Sasson SA, Vlodavsky I. Modulation of fibroblast growth factor- 2 receptor binding, dimerization, signaling, and angiogenic activity by a synthetic heparin-mimicking polyanionic compound. J Clin Invest. 1997; 99(7):1565-1575.

57. Arbibe L, et al. Toll-like receptor 2-mediated NFkappa B activation requires a Rac1-dependent pathway. Nat Immunol. 2000;1(6):533-540.

58. Guha M, Mackman N. The phosphatidylinositol 3-kinase-Akt pathway limits lipopolysaccharide activation of signaling pathways and expression of inflammatory mediators in human monocytic cells. J Biol Chem. 2002;277(35):32124-32132.

59. Liu H, Perlman H, Pagliari LJ, Pope RM. Constitutively activated Akt-1 is vital for the survival of human monocyte-differentiated macrophages. Role of Mcl-1, independent of nuclear factor (NF)-kappaB, Bad, or caspase activation. J Exp Med. 2001;194(2):113-126.

60. Chen $\mathrm{G}$, et al. Inflammatory cytokines and fatty acids regulate endothelial cell heparanase expression. Biochemistry. 2004;43(17):4971-4977.

61. Popivanova BK, et al. Blocking TNF-alpha in mice reduces colorectal carcinogenesis associated with chronic colitis. J Clin Invest. 2008;118(2):560-570.

62. Menzel K, et al. Cathepsins B, L and D in inflammatory bowel disease macrophages and potential therapeutic effects of cathepsin inhibition in vivo. Clin Exp Immunol. 2006;146(1):169-180.

63. Fiebiger E, et al. Invariant chain controls the activity of extracellular cathepsin L. J Exp Med. 2002; 196(9):1263-1269.

64. Gupta RB, et al. Histologic inflammation is a risk factor for progression to colorectal neoplasia in ulcerative colitis: a cohort study. Gastroenterology. 2007; 133(4):1099-1105.

65. Rutter M, et al. Severity of inflammation is a risk factor for colorectal neoplasia in ulcerative colitis. Gastroenterology. 2004;126(2):451-459.

66. Subbaramaiah K, et al. Microsomal prostaglandin E synthase-1 is overexpressed in inflammatory bowel disease. Evidence for involvement of the transcription factor Egr-1.J Biol Chem. 2004; 279(13):12647-12658

67. de Mestre AM, Rao S, Hornby JR, Soe-Htwe T, Khachigian LM, Hulett MD. Early growth response gene 1 (EGR1) regulates heparanase gene transcription in tumor cells. J Biol Chem. 2005;280(42):35136-35147.

68. Bouma G, Strober W. The immunological and genetic basis of inflammatory bowel disease. Nat Rev Immunol. 2003;3(7):521-533.

69. Munitz A, Seidu L, Cole ET, Ahrens R, Hogan SP, Rothenberg ME. Resistin-like molecule alpha decreases glucose tolerance during intestinal inflammation. J Immunol. 2009;182(4):2357-2363.

70. Edelblum KL, Goettel JA, Koyama T, McElroy SJ, Yan F, Polk DB. TNFR1 promotes tumor necrosis factor-mediated mouse colon epithelial cell survival through RAF activation of NF-kappaB.J Biol Chem. 2008;283(43):29485-29494

71. Kelly T, et al. High heparanase activity in multiple myeloma is associated with elevated microvessel density. Cancer Res. 2003;63(24):8749-8756

72. Vlodavsky I, Fuks Z, Bar-Ner M, Ariav Y, Schirrmacher V. Lymphoma cell-mediated degradation of sulfated proteoglycans in the subendothelial extracellular matrix: relationship to tumor cell metastasis. Cancer Res. 1983;43(6):2704-2711. 